\title{
Internacionalização no Ensino Superior e o Brasil como Case Study
}

\section{Internationalization in Higher Education and Brazil as a Case Study}

\author{
Marcia Cristina Alves dos Anjos Almeida \\ Angelo Marcio Oliveira Santanna \\ Edson Pinheiro de Lima
}

O objetivo deste trabalho é realizar um diagnóstico da internacionalização no ensino superior tendo o Brasil como case study. As técnicas de análise de conteúdo e documental foram utilizadas para analisar os dados coletados, com auxílio do software Atlas.ti. A comparação e compreensão qualitativa da internacionalização envolveu três tipos de Universidades Brasileiras: uma IES Privada, sem fins lucrativos, confessional e filantrópica, uma IES Pública Federal e uma IES Privada com fins lucrativos. Verificam-se convergências entre as percepções dos entrevistados sobre a internacionalização das IES brasileiras. Porém, há percepções peculiares no que tange os tipos de IES. No setor público, a importância dos dados e políticas internas em relação a internacionalização tem se nivelado, não apenas por uma consciência internacional, mas por influência das avaliações internas e externas (rankings). A visão do especialista da IES filantrópica é que a internacionalização no Brasil tem muito a caminhar, no sentido de estar mais disseminada e de se ter as universidades trabalhando na direção do real significado de se internacionalizar. Percebe-se na IES Privada, um direcionamento maior para ações de mobilidade acadêmica, e que a internacionalização está sendo trabalhada de duas formas bem categorizadas e definidas: a internacionalização comercial e acadêmica. O ineditismo do estudo está no diagnóstico e comparação da internacionalização entre tipos distintos de IES.

Palavras-chave: Internacionalização, Ensino Superior, Universidades Brasileiras, Classificação de IES.

The objective of this article is to make a diagnosis of internationalization of higher education institutions, $\mathrm{HEI}$, using Brazil as a case study. The techniques of content and document analysis were used to analyze the data collected, with Atlas.ti software support. The comparison and qualitative understanding of internationalization involved three types of Brazilian Universities: a Private non-profit, confessional and philanthropic $\mathrm{HEl}$; a
Recebido em: 15/11/2020 Aprovado em: 08/12/2020

Marcia Cristina Alves dos Anjos
Almeida iD
marciacristinaaaalmeida@gmail.com
Doutoranda em Engenharia de Produção
e Sistemas - Pontifícia Universidade
Católica do Paraná
Ph.D. Student in Production and Systems
Engineering - Pontifícia Universidade
Católica do Paraná
Curitiba/PR - Brasil
Angelo Marcio Oliveira Santanna
angelo.santanna@ufba.br
Doutor em Engenharia de Produção
- Universidade Federal do Rio Grande
do Sul
PhD in Industrial Engineering -
Universidade Federal do Rio Grande
do Sul
Salvador/BA - Brasil
Edson Pinheiro de Lima iD
e.pinheiro@puccpr.br
Doutor em Engenharia de Produção -
Universidade Federal de Santa Catarina
(UFSC)
PhD in Industrial Engineering - Federal
University of Santa Catarina (UFSC)
Curitiba/PR - Brasil


$\checkmark$ Federal Public HEl and a Private HEl for profit. There are convergences between the interviewees' perceptions about the internationalization of Brazilian HEls. However, there are peculiar perceptions regarding the types of HEl. In the public sector, the importance of data and internal policies in relation to internationalization has been leveled, not only by an international conscience, but by the influence of internal and external evaluations or rankings. The vision of the philanthropic IES specialist is that internationalization in Brazil has a long way to go, in the sense of being more widespread and of having universities working towards the real meaning of going international. It is perceived in the Private $\mathrm{HEl}$, a greater direction for academic mobility actions, and that internationalization is being worked on in two well-categorized and defined ways: commercial and academic internationalization. The novelty of the study lies in the diagnosis and comparison of internationalization between different types of HEl.

Key-words: Internationalization, Higher Education, Brazilian Universities, HEl Classification.

\section{Introdução}

O conhecimento é produzido coletivamente no século XXI. As bolsas de estudos não surgem mais de fontes singulares e isoladas de conhecimento profundo, mas de parcerias internacionais, comunidades de intercâmbio e conversas interdisciplinares. A imagem de um estudioso isolado teorizando sozinho é cada vez mais incomum. O conhecimento passa a ser entendido como uma forma que flui rapidamente por meio de sistemas, redes e fronteiras. Espera-se que os alunos adquiram habilidades que lhes permitam acessar esse fluxo de conhecimento. $\mathrm{O}$ conhecimento é mais desejado pelo que pode fazer, não necessariamente pelo que é. Ao invés da ênfase mais tradicional baseada no "o que" é aprendido, hoje o ensino superior está cada vez mais preocupado com o "como" as coisas são aprendidas. A produção de conhecimento também é um processo ativo e aplicável que envolve interconexões, pluralidade, relatividade, colaboração e engajamento com o mundo. A aprendizagem tornou-se assim, mais colaborativa, internacional e global (KAHN; AGNEW, 2017).

Porém, para Kahn e Agnew (2017), embora o foco da aprendizagem tenha se ampliado e deslocado para o processo de aprendizagem, as instituições de ensino superior (IES) têm demorado a responder a essa nova realidade. Limites disciplina- 
res, unidades organizacionais do campus, estruturas de governança consagradas pelo tempo, abordagens tradicionais para estudar o mundo e identidades ancoradas de educador e aluno ainda albergam muitas abordagens em definições territorialmente delimitadas de bolsa de estudos e produção de conhecimento.

A dimensão internacional do currículo progrediu de uma área de estudos e abordagem de língua estrangeira para a integração de perspectivas internacionais, globais, interculturais e comparativas no processo de ensino e aprendizagem e no conteúdo do programa. A mobilidade acadêmica passou de estudante para provedor e mobilidade do programa. A educação transfronteiriça mudou gradualmente de uma estrutura de cooperação para o desenvolvimento de um modelo de parceria. Este novo modelo é instigado pela concorrência comercial (KNIGHT, 2012).

Tendo visto isto, por meio de um estudo qualitativo, utilizando dados primários e secundários e técnicas de análise de conteúdo e documental, o estudo tem como objetivo realizar um diagnóstico da internacionalização das instituições de ensino superior entre três tipos de Universidades Brasileiras. O texto evolui da introdução para os fundamentos teóricos e contextuais que sustentaram o desenvolvimento da pesquisa. Na sequência, o percurso metodológico adotado é descrito. Segue-se a discussão dos resultados, finalizando com as considerações finais e as referências exploradas.

\section{Universidades como Organizações Complexas}

Segundo Junior (2016) as universidades são identificadas por diversos autores como organizações diferenciadas, sendo caracterizadas como sistemas altamente complexos. Essas organizações reúnem muitas áreas do conhecimento e profissionais altamente qualificados, formando grupos de interesse diferentes, que segundo Meyer, Pascucci e Mangolin (2012), se materializam nas estratégias institucionais. Para Alsharari (2018) uma área de preocupação é a governança de sistemas para garantir alta qualidade para as universidades que podem ser estatais, privadas ou com filiais internacionais.

As universidades são classificadas como organizações complexas e possuem uma forma especial de atuar, pela multiplicidade de seus objetivos, aliados 
a heterogeneidade de seu grupo profissional. As universidades são organizações atípicas, que apresentam características distintas de outras burocracias tradicionais. Possuem objetivos conflitantes, difusos e ambíguos. As universidades lidam com o conhecimento, um ativo essencialmente qualitativo e intangível. Possuem tecnologias múltiplas e muita sensibilidade a fatores ambientais que interferem na estratégia (JUNIOR, 2016).

Para Moritz et al. (2012) as instituições são organizações com diferentes objetivos, multidisciplinar, gestora de recursos intelectuais, gera e dissemina conhecimento, propaga debates, arte e música, tornando os objetivos da universidade extensos e complexos, gerando assim, a dificuldade em geri-la. De acordo com Margon e Poubel (2016) essas organizações estão inseridas em um contexto denominado complexo em função de serem caracterizadas pela sua autonomia, não linearidade e ambiguidades. É o caso de hospitais e universidades, por exemplo, cujas decisões e ações são influenciadas por interesses divergentes entre os grupos que os compõem, cada um dos quais com bases de poder suficientes para garantir que seus objetivos sejam legítimos aos propósitos organizacionais. Para Pascucci e Meyer Jr (2013) um desafio que antecede o desenvolvimento da estratégia em tais organizações é conseguir integrar objetivos, frequentemente, conflituosos.

\section{CLASSIFICAÇÃO DAS INSTITUIÇÕES BRASILEIRAS}

As Instituições de Ensino Superior são classificadas pela Lei 9.394/96, e são organizadas por critérios: acadêmico, administrativo e de formação. A Figura 1 organiza a classificação das Instituições de Ensino Superior. 
Figura 1 Classificação das Instituições de Ensino Superior

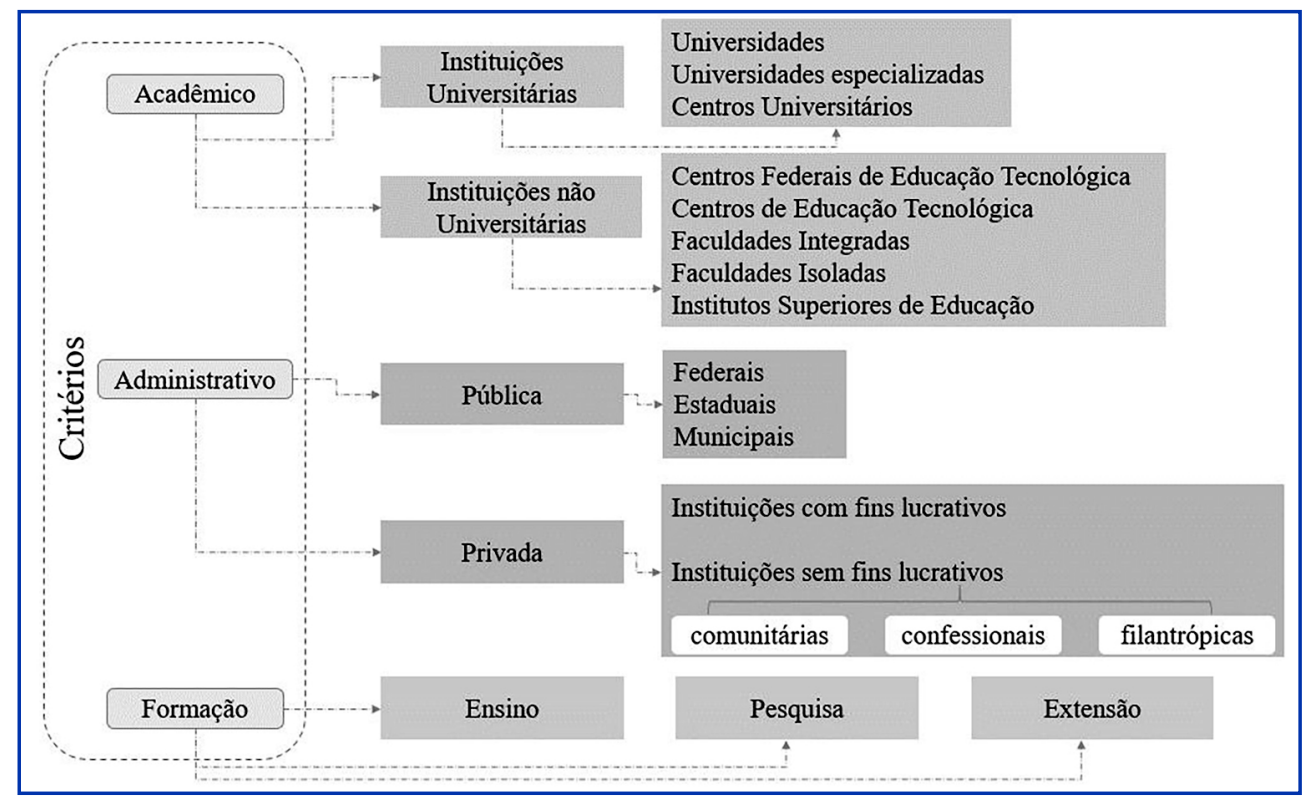

Fonte: a autora baseada na Lei 9.394/96 (2020)

Em relação à organização acadêmica, o Ministério da Educação (MEC) classifica as IES em dois tipos: as instituições universitárias e as não universitárias. As instituições universitárias são divididas em: (i) universidades; (ii) universidades especializadas; (iii) e centros universitários. As instituições não universitárias envolvem: (i) Centros Federais de Educação Tecnológica (CEFET); (ii) Centros de Educação Tecnológica (CET); (iii) faculdades integradas; (iv) faculdades isoladas; (v) e institutos superiores de educação.

$\mathrm{Na}$ organização administrativa a classificação é apresentada em função da natureza jurídica de suas mantenedoras, em públicas e privadas. As instituições públicas são mantidas e administradas pelo Poder Público e são classificadas em: Federais, Estaduais e Municipais. As instituições privadas são mantidas e administradas por pessoas físicas ou pessoas jurídicas de direito privado e estão organizadas em instituições privadas com ou sem fins lucrativos

As instituições privadas com fins lucrativos ou particulares em sentido estrito são instituídas e mantidas por uma ou mais pessoas físicas ou jurídicas de direi- 
to privado. As instituições privadas sem fins lucrativos, são organizadas quanto à vocação social, em: (i) comunitárias, são instituídas por grupos de pessoas físicas ou por uma ou mais pessoas jurídicas, inclusive cooperativas de professores e alunos que incluam na sua entidade mantenedora representantes da comunidade, (ii) confessionais, ou seja, constituídas por motivação confessional ou ideológica, e (iii) filantrópicas, são as instituições de educação ou de assistência social que prestem serviços para os quais foram instituídas e os coloquem à disposição da população em geral, em caráter complementar às atividades do Estado. A organização da formação envolve os níveis de ensino superior brasileiro e tem por base o tripé: ensino, pesquisa e extensão.

\section{INTERNACIONALIZAÇÃO DAS INSTITUIÇÕES DE ENSINO SUPERIOR}

Segundo Knight (2012) o termo internacionalização começou a ser amplamente utilizado pelo setor de ensino superior na década de 1980 para promover estudos internacionais, intercâmbio educacional e assistência técnica. Desde então, houve uma explosão no número e tipos de iniciativas internacionais realizadas por instituições, organizações e governos.

À medida que o século XXI avança, a dimensão internacional do ensino superior está se tornando cada vez mais importante e, ao mesmo tempo, cada vez mais complexa. Segundo Maranhão, Dutra e Maranhão (2017), há uma grande disseminação do tema da internacionalização do ensino superior, mas a compreensão de sua efetividade é muito mais complexa do que realmente se apresenta. Para Mok (2018), a promoção da internacionalização do ensino superior trouxe o fenômeno globalmente conectado no que diz respeito à colaboração interuniversitária e a mobilidade estudantil por meio das fronteiras nacionais. Porém, trouxe um fenômeno localmente dividido quando as pessoas questionam o valor da educação internacional, tendo em vista que existe um número crescente de pessoas que acreditam que o apelo à internacionalização da educação favoreceu a elite e os ricos, marginalizando os pobres.

Para Knight (2014) a internacionalização tornou-se um termo abrangente utilizado para descrever tudo e qualquer coisa remotamente relacionada às dimensões globais, interculturais ou internacionais do ensino superior e, portanto, está perdendo seu caminho. Por tamanha complexidade, a autora enfatiza a importância da 
revisão sobre os valores fundamentais que sustentam a internacionalização, como a cooperação, parceria, troca, benefícios mútuos e capacitação, que cada vez mais estão sendo caracterizados pela competição, comercialização, interesse próprio e construção de status.

Diversas são as formas pelas quais as instituições de ensino superior podem se internacionalizar (GUO; GUO, 2017; MENG, ZHU, CAO, 2017; BEDENLIER; KONDAKCI; ZAWACKI-RICHTER, 2018; WIHLBORG; ROBSON, 2018), e de acordo com Alsharari (2019), as oportunidades em acelerar a internacionalização nas instituições de ensino superior incluem a melhoria geral na qualidade da educação, difusão de tecnologia e criação de uma força de trabalho competente globalmente.

Para Altbach e Knight (2007) as atividades internacionais expandiram dramaticamente em termos de volume, escopo e complexidade. Estas atividades envolvem desde os tradicionais programas de intercâmbio, possibilitando aos alunos o aprendizado sobre outras culturas até proporcionar o acesso ao ensino superior em países onde as instituições locais não podem atender à demanda. Demais atividades, atualizam as perspectivas internacionais e as habilidades dos alunos, melhorando com isso, os programas de língua estrangeira e fornecendo compreensão transcultural.

Com o objetivo de investigar o tema internacionalização das instituições de ensino superior em termos de pesquisas que se desenvolvem, Romani-Dias, Carneiro e Barbosa (2019) identificaram as principais características dos pesquisadores que influenciam a internacionalização das IES, tais como: a experiência acadêmica internacional dos pesquisadores; inserção em redes de colaboração internacional; coautoria internacional; e a experiência internacional em publicações. Segundo os autores, estes são os quatro fatores principais que emergem no nível individual (pesquisador) que impactam positivamente as IES.

Morosini e Dalla Corte (2018) analisaram a internacionalização da educação superior no Brasil, visando estabelecer inter-relações com o contexto da produção do conhecimento e contextos emergentes. Foram pesquisadas teses e dissertações disponíveis no banco de dados do Instituto Brasileiro de Informação em Ciência e Tecnologia. Na perspectiva da expansão, foram identificados os principais elementos que constituem a internacionalização, como exemplo, a formação de redes de pesquisa, cooperação internacional, mobilidade acadêmica e estratégias institucionais. 
Ramos (2018) pesquisou a lógica e os mecanismos da internacionalização da pós-graduação no Brasil. Por meio da aplicação de um questionário com trezentos e vinte e dois coordenadores de pós-graduação, identificou-se a prevalência de uma concepção de internacionalização orientada a atividades como a mobilidade acadêmica. Essa mobilidade é vista como o principal mecanismo de acesso à experiência internacional, à formação de redes e o estabelecimento de colaborações internacionais em pesquisa. $O$ estudo aponta ainda, falta de estratégia nacional e de sistemas administrativos e políticas institucionais adequados na maioria das IES do país, dificultando o desenvolvimento desses laços em um processo mais significante e sustentado de cooperação internacional.

\section{Procedimentos Metodológicos}

Tendo em vista a classificação das IES pela Lei 9.394/96, a coleta de dados desta pesquisa abrangeu três instituições escolhidas de forma não aleatória localizadas no estado do Paraná. Quanto ao critério acadêmico, são classificadas como instituições universitárias. Quanto ao critério administrativo, trata-se de: uma IES Privada, sem fins lucrativos, confessional e filantrópica; uma IES Pública Federal, e de uma IES Privada com fins lucrativos. Quanto ao critério de formação é considerado na pesquisa o tripé, ensino, pesquisa e extensão, pelo entendimento de que a internacionalização é institucional e transversal. Por questões éticas, as identidades das IES envolvidas na pesquisa não serão divulgadas. Para fins de análise, serão identificadas como: IES Federal, IES Filantrópica e IES Privada.

A IES Federal trata-se de uma Universidade Tecnológica Federal, pública, localizada no Estado do Paraná. A IES conta com treze campus no Paraná, com 48 cursos de graduação, 100 curso de especialização, e 72 programas de Stricto Sensu. Conta atualmente com 31.013 estudantes matriculados, 2.549 docentes e 1.176 funcionários técnico-administrativos. Possui como missão, desenvolver a educação tecnológica de excelência, construir e compartilhar o conhecimento voltado à solução dos reais desafios da sociedade. Possui como visão, ser uma universidade reconhecida internacionalmente pela importância de sua atuação em prol do desenvolvimento regional e nacional sustentável. 
A IES Filantrópica trata-se de uma Universidade Católica, privada, confessional e filantrópica, localizada no Estado do Paraná. Está presente em quatro cidades do Estado do Paraná, possui mais de 50 cursos de graduação, 150 cursos de Educação Continuada e 16 programas de Stricto Sensu que compreendem diversas áreas do conhecimento distribuídos em oito escolas: Escola de Negócios, Escola de Comunicação e Artes, Escola de Arquitetura e Design, Escola de Educação e Humanidades, Escola de Ciências da Vida, Escola de Medicina, Escola de Direito e Escola Politécnica. Conta atualmente com mais de 28,6 mil alunos e 1550 professores. Possui como missão desenvolver e difundir o conhecimento e a cultura, além de promover a formação integral e permanente dos cidadãos e profissionais comprometidos com a vida e com o progresso da sociedade. Possui como visão, até 2022, consolidar-se como uma instituição de classe mundial com excelência no ensino, na produção de conhecimento, na prestação de serviços e na relevância social.

A IES Privada trata-se de um Centro Universitário, privado e com fins lucrativos, localizado no Estado do Paraná. Está presente em 1000 polos de apoio presencial espalhados por mais de 700 cidades em todos os Estados Brasileiros, com mais de 400 cursos de graduação, pós-graduação e extensão, sendo 3 programas de Stricto Sensu. Conta atualmente com mais de 250 mil estudantes e 2.200 colaboradores. Possui como missão desenvolver a transformar pessoas por meio da educação. Possui como visão ser reconhecida como organização de excelência para estudar, trabalhar e investir.

Os entrevistados foram escolhidos intencionalmente e atualmente são colaboradores e professores nas instituições pesquisadas. A seleção foi feita considerando que o universo de entrevistados escolhidos pode oferecer contribuições necessárias para responder ao objetivo da pesquisa. Inicialmente, nove convites foram enviados, sendo um retorno negativo e direcionado a outro possível participante e para quatro deles, não se obteve retorno após três tentativas de envio. Para o convite reencaminhado, também não se obteve retorno. Houve retorno positivo para quatro convites, que se referiam aos especialistas da área nas três instituições. $\mathrm{Na}$ IES Federal foi entrevistado o Assessor de Relações Internacionais - Reitoria, na IES Filantrópica, o Diretor de Internacionalização e na IES Privada, as Coordenadoras da Diretoria Estratégica de Relações Internacionais. Todos os entrevistados 
estão no nível estratégico e inteiramente envolvidos com as estratégias e processos de internacionalização das instituições.

Houve a coleta de dados de duas fontes de evidências: as fontes primárias, que envolveram as entrevistas semiestruturadas e as fontes secundárias, referentes aos documentos institucionais disponibilizados pelas instituições participantes da pesquisa. Optou-se pelo uso de questões abertas que proporcionam uma informação mais ampla dos entrevistados. Foram elaboradas dezenove questões de acordo com as etapas contempladas no modelo: consciência, compromisso, planejamento, operacionalização, revisão e reforço. O roteiro original e aplicado encontra-se no Apêndice A. As questões foram formuladas com base no modelo Ciclo de Internacionalização de Knight (1994), que pode ser visualizado na Figura 2.

Figura 2 Ciclo de internacionalização

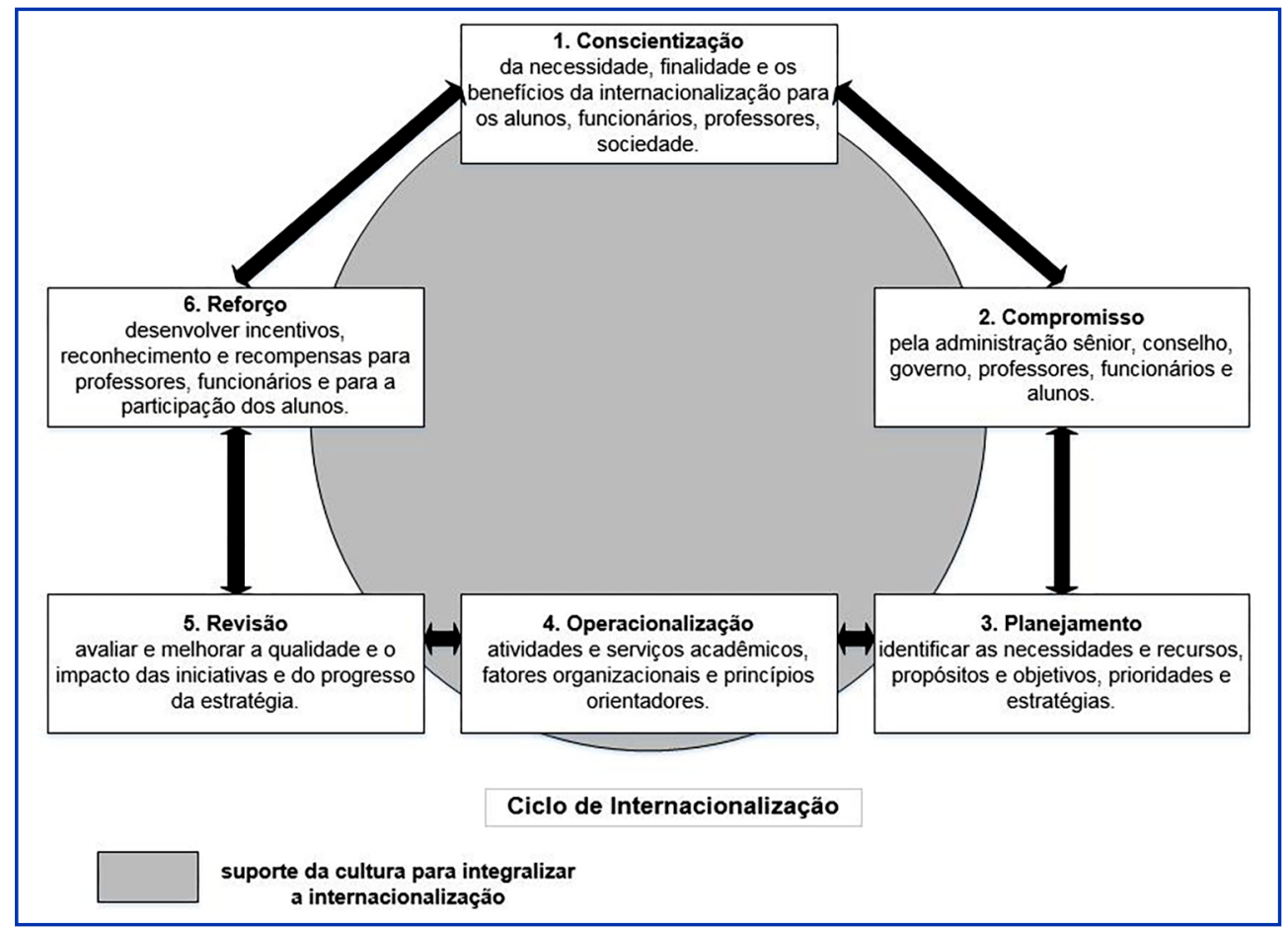

Fonte: KNIGHT (1994, p. 12). 
As entrevistas foram previamente agendadas e realizadas nos meses de junho e julho de 2020 e realizadas de forma online, tendo em vista o período de pandemia causado pelo Coronavírus (COVID 19). O tempo das entrevistas totalizou em três horas e dez minutos. Com o intuito de buscar a convergência e a validação para corroborar com os documentos internos e as entrevistas, as evidências foram transferidas para o software Atlas.ti versão 8', onde puderam ser confrontadas e comparadas, dando início à análise dos dados.

Para os processos e análises qualitativas foram utilizadas as técnicas: análise de conteúdo e análise documental. Segundo Bardin (2011) na análise de conteúdo é a presença ou a ausência de uma dada característica de conteúdo ou de um conjunto de características num determinado fragmento de mensagem que é tomado em consideração. A técnica de análise documental é definida como uma operação ou um conjunto de operações que visa apresentar o conteúdo de um documento de uma forma diferente do original, a fim de facilitar num estado imediato, a sua consulta e referenciação.

A análise de conteúdo compreende técnicas de análise de mensagens por meio de métodos objetivos e sistemáticos, que permitam a inferência relacionado ao conteúdo da mensagem. A análise de conteúdo é um conjunto de técnicas de análise das comunicações. Trata-se de um instrumento que auxilia na obtenção do rigor científico, delimitado por uma diversidade de maneiras e adaptável a um campo de aplicação muito grande: as comunicações (BARDIN, 2011).

Segundo a autora existem diferenças fundamentais entre as duas técnicas. A análise documental trabalha com documentos e a análise de conteúdo com mensagens. O objetivo da análise documental é a representação condensada da informação para consulta e armazenagem. Já a análise de conteúdo objetiva manipular mensagens, para interpretá-las e delas inferir os sentidos que extrapolem o seu conteúdo manifesto lapidando elementos subjetivos (BARDIN, 2011).

De acordo com Bardin (2011) a técnica de análise de conteúdo é organizada em torno de três polos cronológicos: pré-análise, exploração do material selecionado e tratamento dos resultados. A pré-análise é a fase de organização dos documentos selecionados que são organizados no software Atlas.ti e agrupados em um único projeto neste software também chamado de unidade hermenêutica.

As respostas obtidas a partir das entrevistas semiestruturadas foram todas gravadas e posteriormente transcritas. Assim, um conjunto de doze arquivos tota- 
lizando 109 páginas, foram inseridos no software Atlas.ti, também chamados de P-docs. A utilização do software facilitou o processo de análise, armazenagem e controle. O uso do software ocorreu no período de agosto de 2020.

A fase de exploração do material envolve essencialmente a possibilidade de codificação de trechos do texto, inclusão de comentários e construção das redes entre os códigos e entre as citações relevantes dos dados coletados. Dessa forma, após a inclusão dos documentos iniciou-se o processo de codificação. Foram codificadas todas as citações e trechos dos documentos relacionados ao objetivo desta pesquisa. A utilização do software facilitou o processo de codificação, pois possibilitou a análise e a criação de códigos de um documento após o outro. Assim, criado um código, ele pôde ser utilizado para outras citações e trechos.

No primeiro ciclo de codificação (Bardin, 2011) foi necessário criar 40 códigos, que foram empregados em 390 citações. Neste primeiro momento não foram atribuídas relações entre os códigos e entre as citações. Para o segundo ciclo de codificação (Bardin, 2011) com intuito de fazer refinamento dos códigos e citações, foi necessário a criação de 27 relações entre códigos, também chamado de links no Atlas.ti, e foi necessário a criação de 6 novos códigos totalizando 46, empregados em 425 citações, representando um índice de 9,23 citações por código.

Para Bardin (2011), o último estágio da análise de conteúdo, tratamento dos resultados, envolve a inferência e a interpretação dos dados. Neste estágio, o pesquisador faz inferências a partir das relações entre códigos e quotations feitas no estágio anterior, deduzindo de forma lógica, conhecimentos sobre o emissor da mensagem ou fatos sobre o seu meio. Neste estágio, foram geradas as redes no software que permitiu a visualização da relação analítica estabelecida: códigos e quotations foram conectados graficamente em redes. As principais redes que auxiliam no alcance do objetivo desta pesquisa são apresentadas na próxima seção.

\section{Apresentação e Discussão dos Resultados}

A nuvem de palavras é um recurso disponível no Atlas.ti que possibilita, de maneira rápida e visual, ter uma ideia geral do conteúdo de um documento de texto. Assim, é possível observar a frequência das palavras mais citadas dos documentos 
utilizados para análise. A frequência de palavras pode auxiliar também na relação entre os códigos. A Figura 3 apresenta a nuvem de palavras extraída dos 12 arquivos utilizados para a realização da análise neste software.

Figura 3 Nuvem de palavras

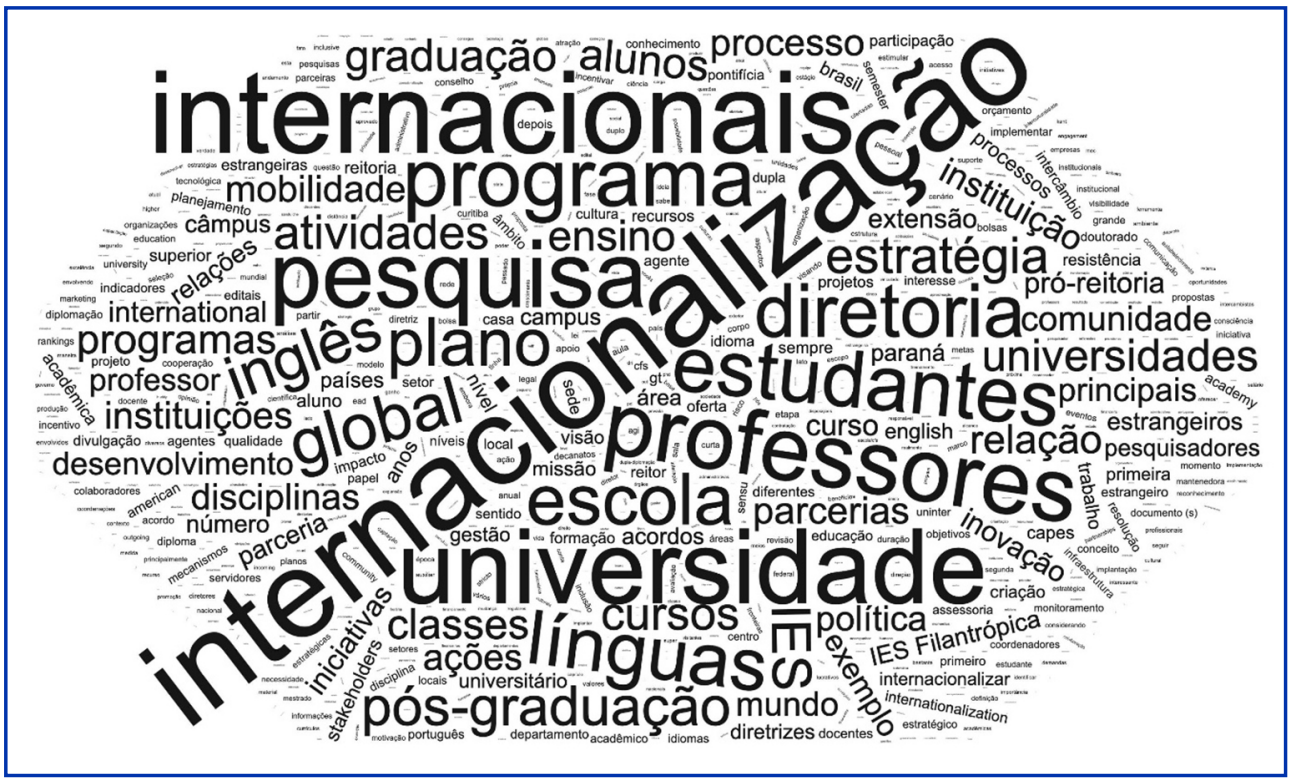

Fonte: Dados de pesquisa elaborados com o apoio do software Atlas.ti

A partir da nuvem de palavras e com base na fundamentação teórica utilizada foi possível codificar as citações. Nos próximos tópicos, serão apresentados os principais resultados e discussões acerca dos códigos encontrados na análise dos dados das três instituições pesquisadas.

\section{A INTERNACIONALIZAÇÃO NAS INSTITUIÇÕES PESQUISADAS}

Nesta seção são apresentados os principais resultados e discussões sobre os principais códigos criados: internacionalização das IES, consciência e cultura de internacionalização, plano/política de internacionalização, metas e objetivos, missão, visão e valores, atividades de internacionalização e posicionamento institucional. 
De acordo com Knight (2015) a internacionalização das instituições de ensino superior, envolve uma série de atividades, políticas e serviços que integram uma dimensão internacional e intercultural para as funções da instituição de ensino, pesquisa e extensão. De acordo com os dados da pesquisa, é possível identificar uma relação direta entre a consciência e cultura de internacionalização com o conceito e a percepção que as instituições possuem sobre o que é de fato a internacionalização, ou seja, como o conceito é aplicado nas IES e nos seus planos, políticas e resoluções de internacionalização.

A consciência e a cultura de internacionalização podem ser entendidas como a importância e o impacto do problema. Essa consciência e cultura são os primeiros passos, no entanto não são suficientes. A internacionalização não pode ser posse de um só grupo, pois precisa agir de maneira inclusiva. Assim, discussões em todo o campus sobre o tema, precisam ser estimuladas para tratar de assuntos, como a necessidade, finalidade, estratégias, questões duvidosas, implicações e benefícios (KNIGHT, 1994).

É possível identificar nas políticas, planos e resoluções de internacionalização disponibilizados pelas IES, que o conceito de internacionalização, consciência e cultura está muito presente na IES Federal e na IES Filantrópica. Percebe-se na resolução apresentada pela IES Privada um foco maior na regulamentação das atividades acadêmicas, projetos, regras, seleção de propostas, funcionamento, prestação de contas e competências dos stakeholders internos. Os objetivos gerais da IES Privada envolvem: garantir a internacionalização, parceria internacional, fomento de intercâmbio, capacitação de docentes, discentes e funcionários, pesquisa, colaboração científica e inovação curricular.

O principal objetivo apresentado na política da IES Federal, é buscar expandir a inserção internacional de excelência da instituição, bem como, internalizar a importância de uma universidade multicultural e conectada com as demandas mundiais. A política desta IES possui base nas definições de: interculturalidade, internacionalização, inserção internacional e universidade de classe mundial. Quanto a IES Filantrópica, sua política é: ter a internacionalização como uma estratégia para aprimorar a qualidade do ensino e da pesquisa, bem como aumentar o alcance do seu impacto social. As políticas destas duas IES apresentam como conceitos bases, a transversalidade e a não dissociação entre ensino, pesquisa e extensão, e 
possui pontos estratégicos estruturados, como a missão, visão e valores. Os conceitos apresentados nos planos e políticas destas IES corroboram com os estudos de Knight (1994; 2015).

Dessa forma, percebe-se por meio das políticas, planos e resoluções uma similaridade na estrutura, diretrizes, estratégias e indicadores, caminhos e entendimento sobre a internacionalização entre as IES Federal e a IES Filantrópica, e um foco maior na regulamentação das atividades de internacionalização na IES Privada. O foco maior em atividades internacionais corrobora com os estudos de Altbach e Knight (2007), que afirmam que as atividades internacionais expandiram drasticamente em termos de volume, escopo e complexidade ao longo das duas últimas décadas.

Os entrevistados elencaram as principais atividades de internacionalização de suas instituições, e dentre elas são apresentadas atividades relacionadas a: mobilidade acadêmica, dupla diplomação, programas especiais (agente de internacionalização, American Academy, Global Classes, Embaixador), internacionalização em casa, programa de bolsas.

A IES Filantrópica apresenta alguns programas considerados super especiais para a Universidade, conforme relata o Diretor de Internacionalização da IES:

(1) os planos de internacionalização das Escolas, os programas especiais, como intercâmbio, duplos diplomações, programas de curta duração, os programas super especiais, como, o American Academy da universidade, o Global Classes, os próprios AGI's, né, eu não conheço nenhuma outra IES Brasileira que tem essa figura do Agente de Internacionalização nas Escolas, né, trabalhando dentro das Escolas. Todos esses programas muito especiais nossos e que tem funcionado muito bem para criar essa cultura da internacionalização que está se tornando mais natural hoje em dia na universidade. Global Classes, que é esse programa que introduz o inglês dentro da sala de aula [...] Eu acho que hoje implementados, eu diria que o Global Classes, o AGI que é esse programa que consolida o agente de internacionalização como um gestor dentro da estrutura das Escolas, e o American Academy, é a joia da nossa coroa, é o programa de internacionalização mais vistoso que nós temos junto com o Global Classes. (Entrevistado 2)

Para a IES Federal, a dupla diplomação é uma atividade de internacionalização que a IES conseguiu desenvolver muito bem. Segundo o Assessor de Relações Internacionais as principais atividades de internacionalização envolvem: 
(2) Dupla Diplomação, Embaixador, que é o professor que vai lá fora fazer o papel de visibilidade de aproximação [...] eu diria que agora apesar de muito pequeno, é a internacionalização em casa, que é uma das iniciativas novas e que está surgindo vários parceiros [...]. Eu diria que se a universidade fosse vista de fora, eu digo assim: ah, no que vocês são bons em internacionalização? Eu diria: duplo diploma. Então, eu diria que [isso] é uma especialidade nossa, e são poucas. Somos modestos ainda em internacionalização, mas é algo que a gente conseguiu desenvolver bem, que é o funcionamento da dupla diplomação. (Entrevistado 1)

Para a IES Privada, por se tratar de uma IES com fins lucrativos, o posicionamento frente a internacionalização é percebido de duas maneiras: a internacionalização comercial, que está mais relacionada ao branding, lucros e abertura de polos, e a internacionalização acadêmica, que está mais relacionada às atividades de internacionalização, e que de acordo com as entrevistadas: (3) "a consciência da instituição do que é internacionalização ainda está vinculada a mobilidade”. (Entrevistados 3 e 4).

Assim, as principais atividades de internacionalização da IES, conforme relatam as Coordenadoras da Diretoria Estratégica de Relações Internacionais, envolvem a: mobilidade acadêmica, programa de bolsas Santander Universidades e a criação de uma nova Diretoria que dará suporte a essas e a novas atividades internacionais. É possível verificar ao longo da análise o surgimento de atividades de internacionalização para a modalidade de ensino a distância (EAD) nas três instituições (TRESHCHEVSKY; IGOLKIN; SHATALOV, 2019).

\section{PRIORIDADES E ESTRATÉGIAS DE INTERNACIONALIZAÇÃO}

Nesta seção serão apresentados os principais resultados e discussões acerca dos códigos: prioridade institucional, estratégias de internacionalização, branding e comunicação internacional e visibilidade internacional.

A prioridade de internacionalização é percebida de formas diferentes para as três instituições. Para a IES Federal, quando questionado sobre a prioridade entre ensino, pesquisa e extensão, o entrevistado explicou que em termos práticos, a Universidade foca inicialmente em melhorar nos rankings internacionais, ou seja, aumentar a visibilidade. Outro ponto, é a internacionalização dos programas de forma que tenham uma produção científica efetiva com parceiros internacionais. Outro ponto ainda, é dar acesso aos servidores e aos alunos as diferenças culturais e que 
eles tenham acesso a produções com parceiros internacionais. Para o Assessor de Relações Internacionais:

(4) essa diferença de metodologia potencializa muito a capacidade desse aluno de pesquisar e de produzir no futuro, então esse é um dos grandes objetivos da internacionalização, né, fazer com que os alunos tenham essa visão de mundo, mesmo sem sair das suas cidades. (Entrevistado 1)

Em relação aos níveis de ensino, para a IES Federal não há prioridade, mas necessidades diferentes para a Pós-Graduação e para a Graduação. Para a Pós-Graduação a prioridade de internacionalização está relacionada às citações e às parcerias internacionais de pesquisa. Para a Graduação está relacionada a dupla diplomação. A IES Privada, tem por prioridade o ensino e a extensão e todas as decisões de internacionalização obrigatoriamente envolvem a Pós-Graduação e a Graduação. A Figura 4 apresenta o código, as citações e as relações entre elas.

Figura 4 Prioridade de Internacionalização

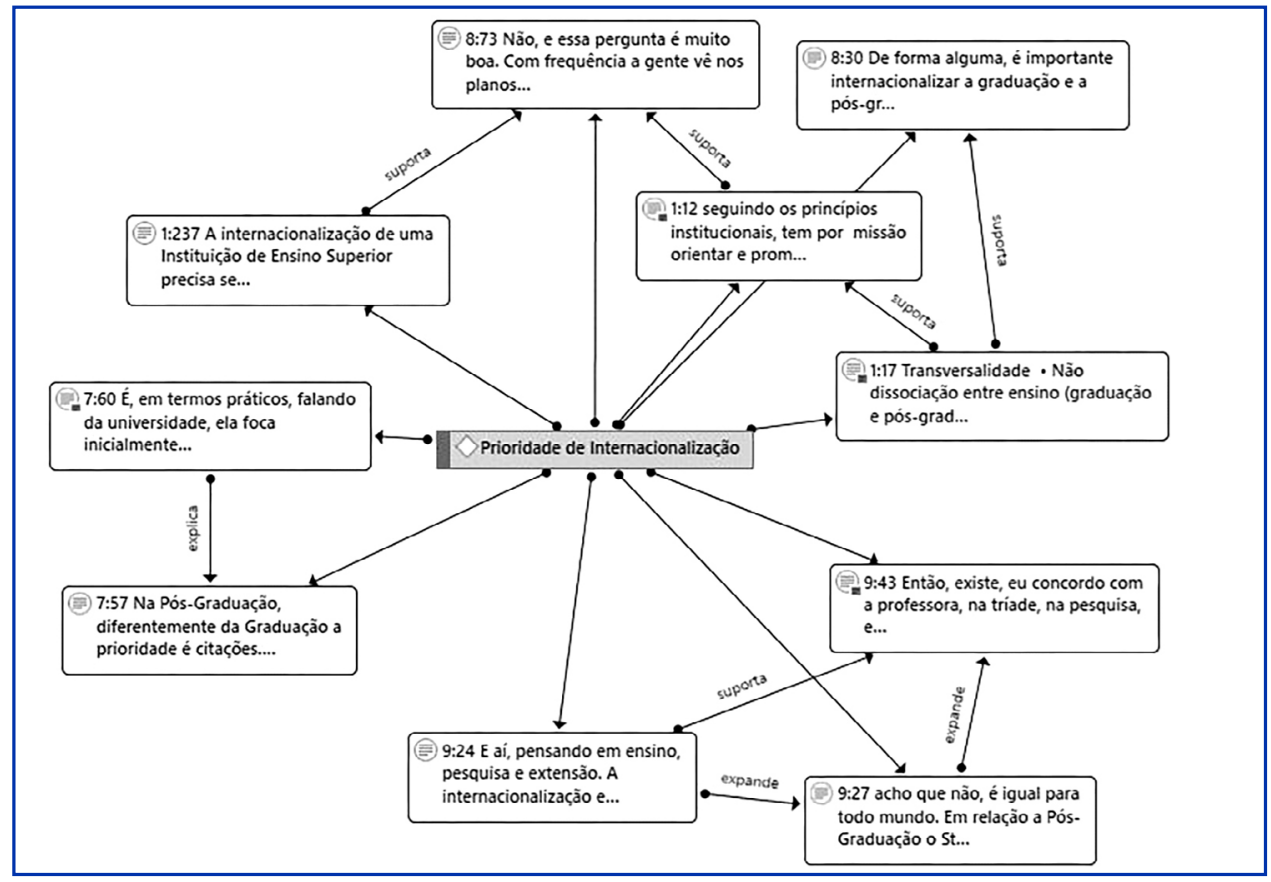

Fonte: Dados de pesquisa obtidos com o apoio do software Atlas.ti 
Para a IES Filantrópica, não há dissociação entre os níveis de ensino, pesquisa e extensão. A internacionalização de uma Instituição de Ensino Superior precisa ser percebida e vivenciada em todos os níveis da instituição, como ferramenta fundamental na contribuição para se atingir a excelência nas suas atividades acadêmicas e administrativas, das mais simples às mais complexas. Para o Diretor de Internacionalização:

(5) De forma alguma, é importante internacionalizar a graduação e a pós-graduação e sempre seguindo a mesma orientação e o mesmo conceito [...] com frequência a gente vê nos planos de internacionalização das universidades, as que tem plano, e nem todas tem, poucas tem, aliás. Essa distinção. Então, geralmente os planos são assim, internacionalização da graduação, vai para um lado, a internacionalização da pesquisa, e vão para aquele lado, e assim vai. Nós deliberadamente decidimos não fazer dessa forma. Nós achamos que a internacionalização é transversal, ela cobre todos esses aspectos e a universidade como instituição ela pode desenvolver um plano que tenha impacto em todos esses aspectos ao mesmo tempo. Então, nós não sentimos a necessidade de compartimentalizar dessa forma que você falou ou de priorizar uma ou outra área. (Entrevistado 2)

De acordo com Ayoubi e Massoud (2007) alguns fatores devem ser incluídos para o desenvolvimento da estratégia internacional, como: programas de ensino, parcerias, intercâmbio de alunos e funcionários, atividades de pesquisa, novas disciplinas, atendimento ao cliente e habilidades de marketing, análise de custo-benefício e riscos, identidade e regulamentação, especialização e o aumento do uso de marcas para explorar ativos de reputação.

Foi identificado as estratégias de internacionalização observadas nos documentos institucionais da IES Federal e da IES Filantrópica. Verificam-se similaridades entre as estratégias apresentadas pelas as IES e a fundamentação teórica (EGRON-POLAK, 2007). Algumas das estratégias, envolvem: promover a visibilidade da IES em âmbito internacional; promover a internacionalização interna de setores, processos, pessoas e infraestrutura; expandir a cooperação internacional em pesquisa e inovação; internacionalização dos currículos; e incentivo às iniciativas de duplas ou múltiplas diplomações.

Knight (2014) explica que cada vez mais a internacionalização está sendo caracterizada pela competição, comercialização, interesse próprio e construção de status. Este ponto da fundamentação teórica está diretamente relacionado ao bran- 
ding, comunicação e a visibilidade internacional. Pela análise dos dados, é possível identificar 25 citações ligadas a esses códigos e 4 delas em comum aos dois códigos. A Figura 5 apresenta a rede dos códigos branding e comunicação internacional e visibilidade, bem como, as citações das relações entre elas.

Figura 5 Branding e comunicação internacional e visibilidade

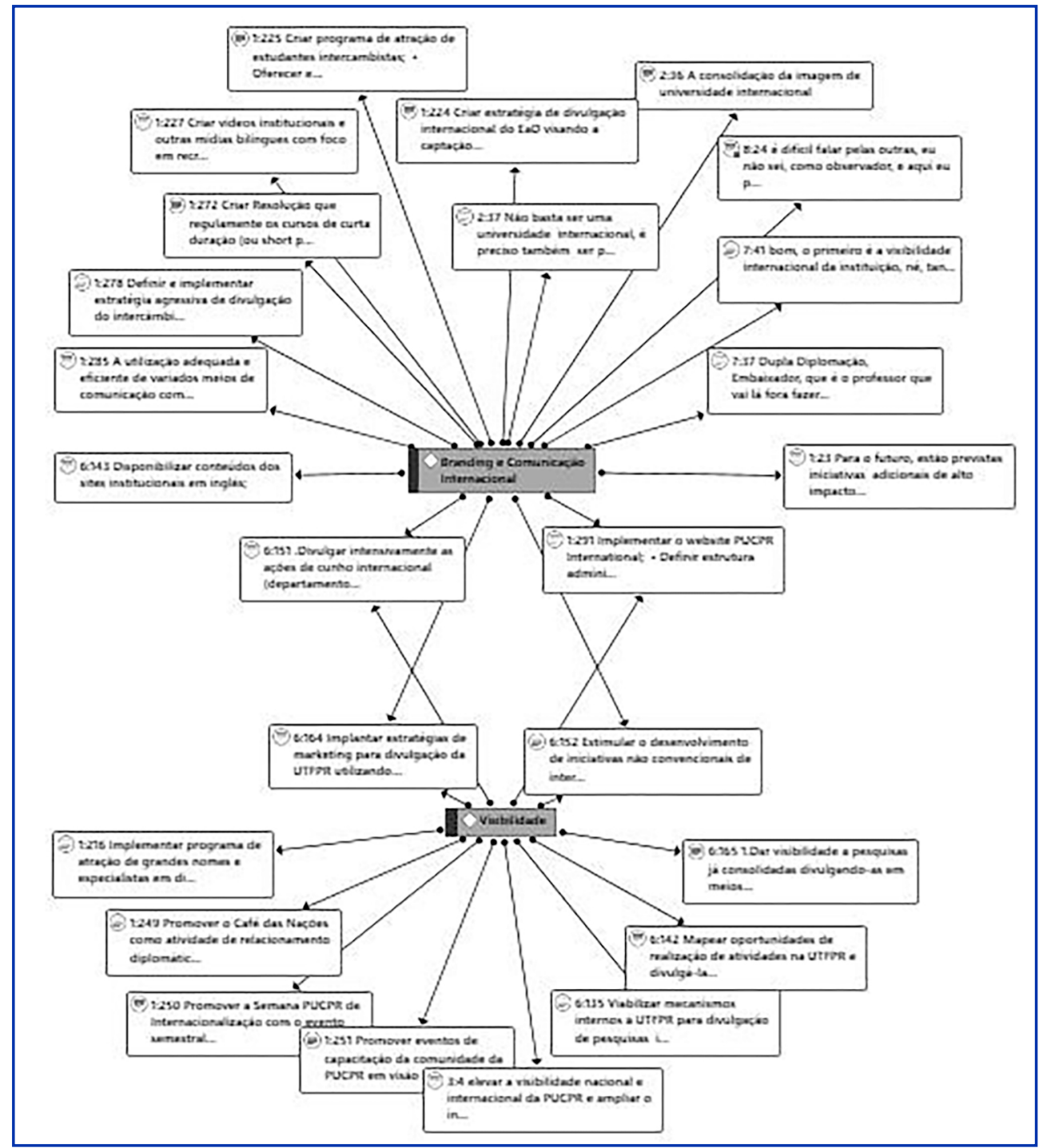

Fonte: Dados de pesquisa obtidos com o apoio do software Atlas.ti 
As atividades comuns mapeadas aos códigos (branding e comunicação internacional e visibilidade) estão relacionadas a IES Federal e a IES Filantrópica, e envolvem principalmente, a divulgação intensiva das ações de cunho internacional e a implantação de estratégias de marketing para divulgação das IES utilizando de mecanismos internos, como páginas, website e outros materiais de divulgação. Embora não tenham sido mapeadas citações para esses códigos na IES Privada, uma das formas de internacionalização da IES é a comercial, portanto, entende-se que esses aspectos estejam intrínsecos a ela.

\section{INTERNACIONALIZAÇÃO EM CASA}

Nesta seção serão apresentados os principais resultados e discussões acerca dos códigos: internacionalização em casa, internacionalização dos professores, alunos e quadro administrativo, incentivos e recompensas, parcerias e acordos estratégicos, mobilidade acadêmica (incoming e outgoing), integração e infraestrutura.

A internacionalização em casa, ou seja, a internacionalização independentemente da mobilidade internacional, é um conceito que cada vez mais está surgindo quando se fala em internacionalização das instituições de ensino superior. Para Knight (2012) a evidência dessa mudança ocorre na bifurcação da internacionalização em dois pilares interdependentes, "em casa" e "no exterior". Corroborando com essa fundamentação teórica, para a IES Filantrópica a verdadeira transformação acontece de dentro para fora.

(6) Democratizar a internacionalização através de uma ação ampla e transversal de internacionalização em casa, cujo objetivo é favorecer a inclusão da comunidade acadêmica de estudantes, professores e colaboradores no ambiente global independentemente da mobilidade internacional. (Entrevistado 2)

Para a IES Federal, a internacionalização em casa é uma missão muito importante da IES. Para a IES Privada, a internacionalização em casa acontece por meio de um grupo de trabalho de internacionalização, que envolve a Reitoria, Diretores de Escolas e Professores, que juntos pensam e aprovam atividades de internacionalização para toda a comunidade acadêmica.

Segundo Huang (2017) a internacionalização institucional é considerada um aspecto importante no desenvolvimento do ensino superior de hoje. O desenvol- 
vimento da competência intercultural deve ser considerado como um resultado importante da internacionalização institucional dos alunos. Para o autor o ensino de inglês e ações relacionadas são recursos de fácil acesso que podem ser plenamente utilizados para promover a competência intercultural dos alunos nas universidades.

Em relação as ações de internacionalização, para a IES Privada elas envolvem: atender à necessidade de formação e capacitação de docentes, discentes e funcionários; incorporar o acadêmico em atividades voluntárias ou não, relacionadas à negociação e cooperação com universidades internacionais, oportunizando a consolidação da formação acadêmica dos docentes, discentes e funcionários, ao desenvolvimento de pesquisas conjuntas, as parcerias de Gestão e de Desenvolvimento de Tecnologias; atender ao Plano de Qualificação Docente, oportunizando aos professores condições de aprofundamento e/ou aperfeiçoamento de seus conhecimentos científicos, tecnológicos e profissionais e cursos de idiomas.

Para a IES Filantrópica, as ações de internacionalização envolvem: (i) a oferta sistemática de cursos de inglês com o objetivo de ter este idioma como segunda língua da IES para professores, estudantes e colaboradores; (ii) o estudo da viabilidade de um programa interno de bolsas de mobilidade de estudantes de todos os níveis, professores, pesquisadores e colaboradores; (iii) a promoção de programas de difusão e treinamento no conceito de English as Media of Instruction - EMI. De acordo com Valcke, Murphy e Costa (2017), nas últimas duas décadas, a EMI surgiu como uma ferramenta para a internacionalização do ensino superior como uma resposta necessária às forças da globalização. Como resultado do desenvolvimento do ensino superior na Europa e no resto do mundo, a EMI tornou-se uma tendência crescente (VALCKE et al., 2017).

Para a IES Federal as ações de internacionalização envolvem: o desenvolvimento de parcerias internacionais que facilitem a mobilidade de servidores e estudantes, estímulo a docentes e técnicos-administrativos a formação e a estudos e a pesquisas fora do Brasil; capacitar servidores docentes e administrativos para a internacionalização de atividades; apoio aos servidores na participação de Editais/Chamadas internacionais; identificar demandas para cursos de línguas para professores, servidores e alunos; proporcionar oportunidades para que estudantes da IES participem de ações de mobilidade (mobilidade simples, dupla- 
-diplomação), de pelo menos um semestre, com universidades de outros países, com reconhecido prestígio acadêmico; prospectar oportunidades de estágio para alunos da IES em outros países; viabilizar a participação de alunos da IES em cursos à distância oferecidos por universidades de outros países; oferecer oportunidades de empreendedorismo tecnológico, criação de startups ou de programas de aceleração internacionais.

Os incentivos e as recompensas relacionadas a ações de internacionalização são diferentes nas três IES. Na IES Federal não há recompensas ou programas de remuneração. É percebido a existência de incentivo e de motivação para essas ações, da valorização do docente e do quadro administrativo em atividades internacionais, como, por exemplo, uma homenagem a um pesquisador com destaque internacional. Verifica-se a oferta de bolsas de estudos em cursos de idiomas nas IES Filantrópica e na IES Privada para toda a comunidade da IES. Na IES Privada há programa de bolsas de mobilidade acadêmica para os alunos, remuneração financeira para os professores que têm produção científica e há incentivos aos professores para a participação de eventos e congressos internacionais.

Na IES Filantrópica os professores dos programas do Stricto Sensu são remunerados por publicações de alto impacto, possuem auxílio para publicação e revisão profissional de artigos em inglês. A IES trabalha com a pontuação no programa de progressão de carreira na universidade para os professores que aderem ao Global Classes, e há remuneração para os professores que atingem o nível III do programa. A IES estuda formas de ampliar programas de incentivo a comunidade acadêmica (quadro administrativo e alunos). A Figura 6 apresenta a representação gráfica do código Internacionalização em Casa, e a relação direta deste código com os demais códigos. 
Figura 6 Internacionalização em casa

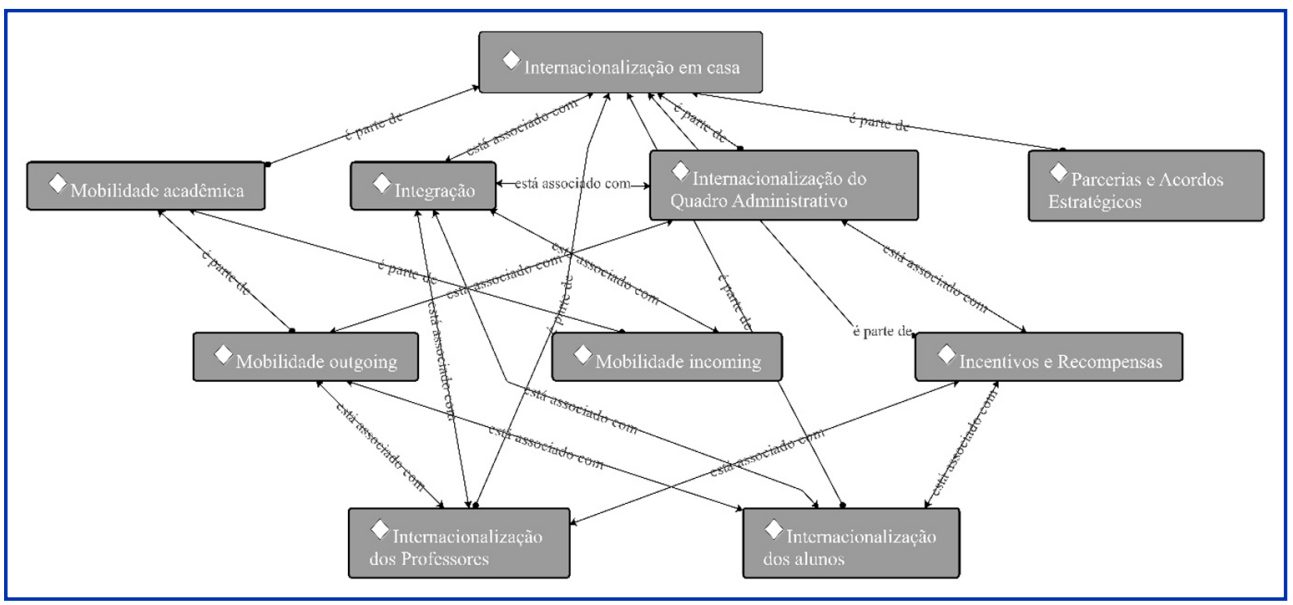

Fonte: Dados de pesquisa obtidos com o apoio do software Atlas.ti

Em relação as parcerias e acordos estratégicos percebe-se nas três instituições o desejo de se estabelecer parcerias e acordos que sejam produtivos, que promovam de fato o potencial de pesquisa, a mobilidade acadêmica, a inovação, a visibilidade internacional, ou seja, que se estabeleça nessas relações a qualidade e não apenas a quantidade.

Snodin (2019) pesquisou sobre as experiências de mobilidade de estudantes internacionais no ensino superior tailandês. Os resultados mostraram como fatores de atração importantes, a disponibilidade de bolsas de estudo, referências "boca a boca" e a proximidade geográfica e cultural de um país de origem. A vida acadêmica personalizada e o forte apoio a pesquisa nas disciplinas também apareceram como pontos fortes para a mobilidade acadêmica.

Nas três instituições percebem-se estratégias e objetivos relacionados a mobilidade. A mobilidade acadêmica está relacionada a mobilidade incoming (entrada) e a mobilidade outgoing (saída). Foi possível identificar que a IES Federal é mais efetiva com a mobilidade outgoing e explica a baixa mobilidade incoming ao fato da falta de visibilidade internacional do Brasil, que gera consequentemente, a falta de interesse. A IES Privada apresenta também pontos mais fortes relacionados a mobilidade outgoing. Na IES Filantrópica, foi possível perceber pontos relacionados as duas mobilidades. 
A internacionalização em casa está diretamente relacionada a integração, que está diretamente relacionada a mobilidade incoming, ou seja, promover a integração do professor, aluno ou profissional estrangeiro à cultura brasileira, aumentando e facilitando a sua interação com a comunidade local. A infraestrutura é um ponto que surge relacionado a isto nos planos e políticas da IES Federal e da IES Filantrópica, e que vão desde equipamentos disponibilizados a pesquisadores estrangeiros, sede própria para programas de internacionalização, criação de microambientes internacionais para favorecer a integração e residências universitárias.

\section{GESTÃO E DESEMPENHO}

Nesta seção serão apresentados os principais resultados e discussões acerca dos códigos: gestão e desempenho, stakeholders internos e externos, indicadores de internacionalização, receitas e investimentos e processos acadêmicos e administrativos.

As atividades e papeis da gestão das áreas internacionais dentro das IES estudadas, basicamente envolvem: mapeamento das demandas, definição das políticas, previsão orçamentária, gestão dos programas internacionais, facilitar os processos acadêmicos e administrativos, incentivo, motivação e orientação. Entre os principais stakeholders internos, estão: a Reitoria, as Pró-reitorias, as Escolas, departamentos administrativos e acadêmicos.

A atuação da gestão da Diretoria de Internacionalização da IES Filantrópica, envolve a autonomia e a responsabilidade de definir os rumos da internacionalização na Universidade. A atuação da IES Privada envolve um Grupo de Trabalho de Internacionalização (GT), onde se pensam e são aprovadas ações de internacionalização junto à Mantenedora. A atuação da gestão da IES Federal envolve a orientação, consciência e o apoio às iniciativas de internacionalização, bem como a operacionalização de tais iniciativas junto com Escritório Internacional da Reitoria.

Os entrevistados foram questionados sobre o papel desempenhado pelos órgãos governamentais no processo de internacionalização das IES de forma geral. A IES Federal e a IES Filantrópica compartilham da mesma opinião ao dizer que esse papel é pequeno, modesto e por muitas vezes, raro. Estas IES afirmam que apoios governamentais, eventualmente, acontecem via editais de bolsas, e embora seja 
interessante, a ocorrência destes editais é baixa e incerta. Sendo assim, o apoio governamental é esporádico e circunstancial. Para a IES Privada esse papel se configura via avaliações, instrumentos e diretrizes do MEC - Ministério da Educação do Brasil, da Coordenação de Aperfeiçoamento de Pessoal de Nível Superior, da sigla brasileira CAPES, e do Sistema Nacional de Avaliação da Educação Superior, da sigla brasileira SINAES.

Os resultados da pesquisa de Prolo et al. (2019) revelam que o programa 'Ciências sem Fronteiras' potencializou a exposição das universidades brasileiras no ambiente internacional, favoreceu a criação de parcerias e redes acadêmicas internacionais, e influenciou na definição do modelo de internacionalização do Ensino Superior desejado pelo Governo brasileiro. Segundo estes autores, na medida em que o 'Ciências sem Fronteiras' contribuiu para uma curva de aprendizagem e influenciou na decisão de se avançar em um processo de internacionalização mais amplo e organizado, ampliou as condições que criam um ambiente internacional no interior das universidades brasileiras. É observado que a percepção dos entrevistados contradiz com os resultados da pesquisa de Prolo et al. (2019). A Figura 7 apresenta as percepções dos entrevistados, bem como as relações entre as citações. 
Figura 7 Stakeholders externos

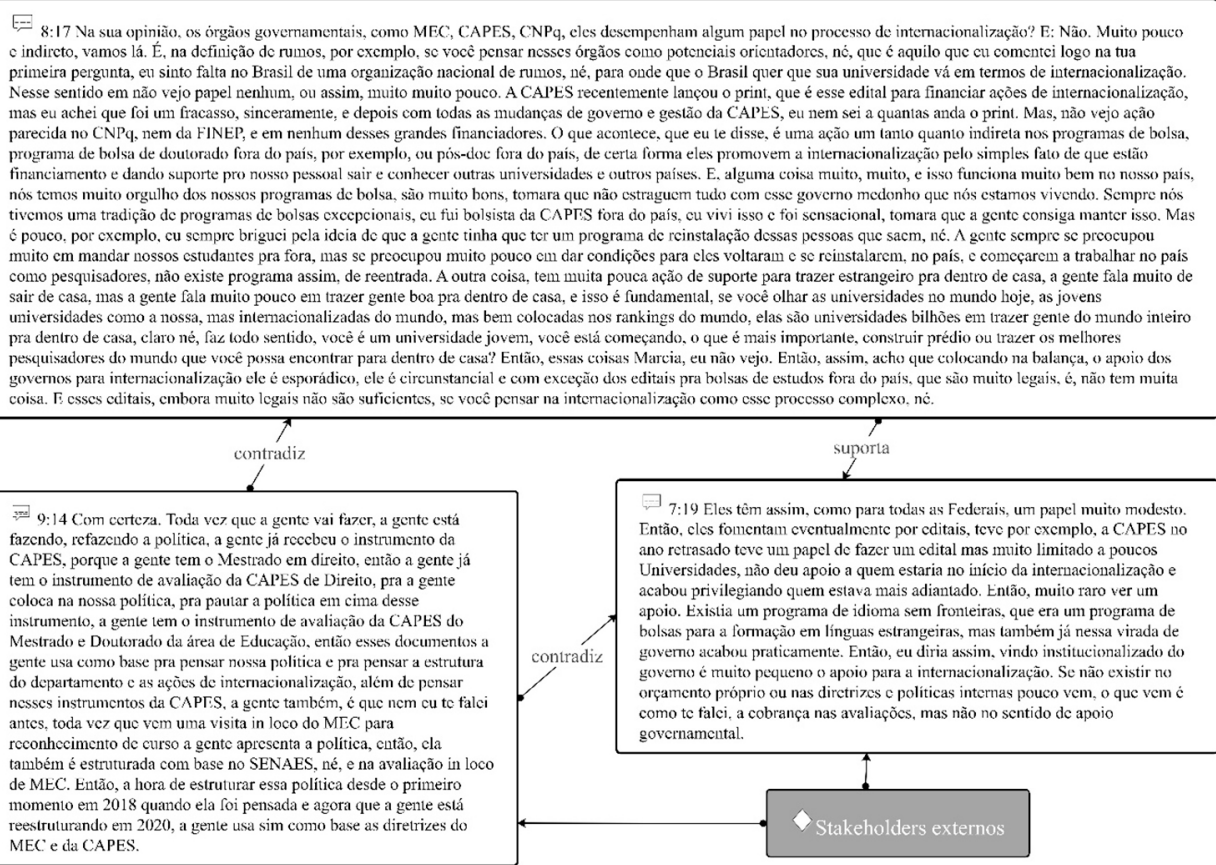

Fonte: Dados de pesquisa obtidos com o apoio do software Atlas.ti

De acordo com Patel (2017) a internacionalização se tornou mais do que uma palavra da moda nos últimos anos. Tornou-se um importante investimento, gerando receitas substanciais, e é considerado um imperativo em seu parentesco com marcas e classificações no ensino superior internacional. A questão das receitas e dos investimentos para a internacionalização apresenta aspectos diferentes entre as IES estudadas. De acordo com o Assessor de Relações Internacionais da IES Federal, por se tratar de uma Universidade Pública existe um certo orçamento e esse orçamento flutua, as vezes zerando, as vezes sobrando, pois não há uma previsão de quando virá ou de quando será cortado. $O$ relato abaixo responde o questionamento sobre impacto financeiro em virtude da internacionalização:

(7) [Somos] uma universidade pública, então ela não tem fins lucrativos e nenhum setor arrecada nenhum recurso em função disso. A Universidade não passou a ter mais orça- 
mento por conta disso [internacionalização]. Existia uma iniciativa do governo, chamada PDU, que era um orçamento que vinha para ajudar nos escritórios internacionais. Isso era pequeno e acabou. Então, em termos financeiros é só déficit mesmo, porque se a Universidade não tirar do próprio bolso, do próprio orçamento para passagens e eventos internacionais, ela não tem internacionalização. Então, nesse sentido é negativo. (Entrevistado 1)

A IES Filantrópica possui orçamento que é discutido e aprovado anualmente para o investimento em ações de internacionalização, ou seja, o orçamento é matricial e descentralizado. Para a IES Privada, o orçamento para ações de internacionalização sempre esteve voltado ao Stricto Sensu. Com a chegada da Diretoria de Relações Estratégicas e o planejamento voltado para área esse orçamento passará a existir para os demais níveis de ensino a partir de 2021. A Figura 8 apresenta a representação gráfica dessa comparação.

Figura 8 Receitas e Investimentos

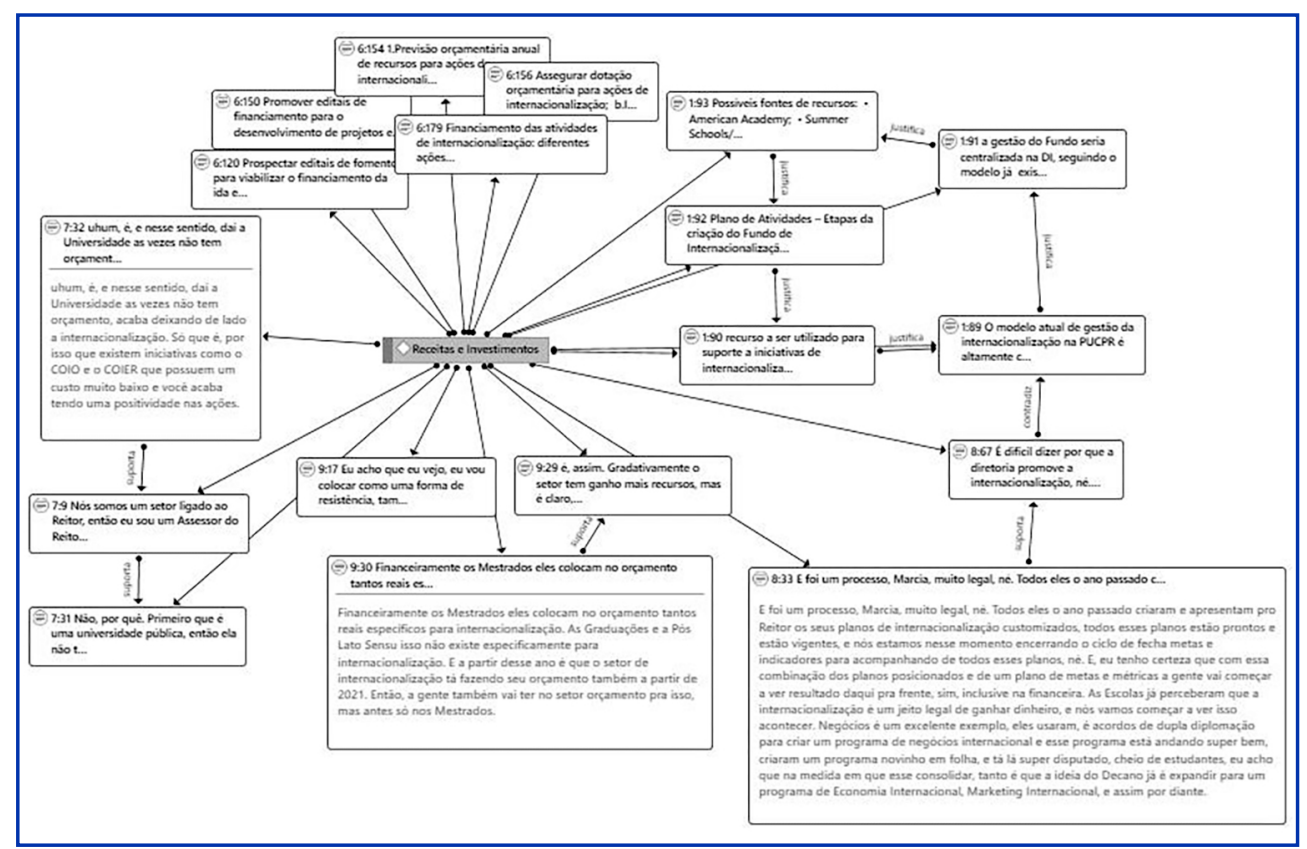

Fonte: Dados de pesquisa obtidos com o apoio do software Atlas.ti 
De acordo com Bas, Boquera e Carot (2017) medir a internacionalização das instituições de ensino superior é um processo complexo, pois muitos parâmetros devem ser levados em consideração além da mera compilação de dados. Segundo Seeber (2019) o contexto da educação superior apresenta de fato características específicas que podem dificultar comparações, e os processos políticos e sociais ocorridos nas últimas décadas aumentaram ainda mais a complexidade. A crescente disponibilidade de dados sobre sistemas de ensino superior, instituições e seus membros cria oportunidades para pesquisas comparativas que adotam uma abordagem quantitativa. $O$ valor de estudos futuros depende crucialmente da capacidade de reconhecer e abordar alguns dos principais desafios metodológicos existentes na pesquisa comparativa quantitativa no ensino superior. Tais fundamentos corroboram com o discurso dos entrevistados a respeito dos indicadores de desempenho de internacionalização de IES. Para os entrevistados, estes, são considerados fundamentais, pois oferecem ferramentas de acompanhamento com objetivo principal de saber o que está funcionando e o que não está, bem como, motivam e são os grandes potencializadores da atividade de internacionalização.

Os planos e políticas de internacionalização da IES Federal e da IES Filantrópica apresentam os indicadores de internacionalização para a medição de todas as estratégias propostas. A Resolução da IES Privada não apresenta indicadores de internacionalização. Para o Diretor de Internacionalização da IES Filantrópica, três indicadores de internacionalização são considerados transversais: (i) produção científica de impacto internacional; (ii) disciplinas em inglês ou maior presença do inglês em rotinas acadêmicas; e (iii) a mobilidade internacional incoming, A IES Federal mede a internacionalização por meio do monitoramento permanentemente de todos os rankings, realiza o preenchimento das informações nos rankings e realiza o balizamento, verificando em quais dimensões a IES melhorou ou piorou a cada ano. Para a IES Privada os indicadores são importantes para se obter aporte da IES em relação a internacionalização e para apresentar evidências aos órgãos governamentais.

Os processos técnico-administrativos e acadêmicos relacionados as ações internacionais serão melhor desenvolvidas se o membro internacional for tratado em condições de igualdade pelos estudantes, professores e colaboradores locais. Existe, por exemplo, a preocupação dos entrevistados quanto a adequação inter- 
nacional para processos jurídicos, financeiros, tecnológicos, de gestão de pessoal, comunicação e marketing; e quanto aos procedimentos para validação de créditos de outros países. Estes procedimentos terão mais sucesso à medida que estejam plenamente incorporados à rotina dos processos. Os processos técnico-administrativos e acadêmicos nas três IES envolvem: (i) a matrícula de alunos internacionais; (ii) a mobilidade acadêmica; (iii) a dupla diplomação; (iv) a gestão das disciplinas ofertadas em outros idiomas; (v) a emissão de documentos acadêmicos; e (vi) os processos seletivos calcados em programas internacionais.

\section{QUALIDADE NO ENSINO, PESQUISA E EXTENSÃO}

Nesta seção serão apresentados os principais resultados e discussões acerca dos códigos: qualidade no ensino, pesquisa e extensão, potencial de pesquisa, inovação no currículo, idioma e disciplinas em outros idiomas.

De acordo com os resultados da pesquisa, a internacionalização das instituições de ensino superior está diretamente relacionada a qualidade no ensino, pesquisa e extensão, e as três instituições estudadas apresentam aspectos relacionados a esse código. A qualidade no ensino está relacionada a inovação nos currículos, oferta de disciplinas em outros idiomas e aos idiomas propriamente ditos. A qualidade na pesquisa está relacionada ao seu potencial de desenvolvimento internacional, e a qualidade na extensão está relacionada a oferta de disciplinas em outros idiomas, aos cursos de idiomas e aos programas de curtas duração.

Em relação a influência da internacionalização para a inovação no currículo, é possível perceber na Resolução disponibilizada pela IES privada, o estímulo a aproximação das estruturas curriculares, inclusive a equivalência e o reconhecimento mútuo de créditos obtidos em instituições parceiras. Os relatos das Coordenadoras mostram essa evidência, inclusive relacionada as disciplinas em inglês e a cursos de extensão em outros idiomas:

(8) [...] é mais difícil perceber o vínculo direto entre internacionalização e atualização de currículo ou de metodologias, né. Mas, eu acho que existe um pouquinho, eu acho que tem, por exemplo. A XXXX acabou de pedir para gravar uma disciplina do Direito em inglês e eu fiz lá toda a revisão e eu acho que de uma maneira ou de outra isso aconteceu, pela visão da internacionalização em si da instituição. O curso de Relações Internacionais e Comércio Exterior também tem uma disciplina em inglês e isso é um impacto direto da internacionalização. Então, eu vejo sim esses pontos, a gente ainda, claro, 
caminhando tímido, mas tem sim a internacionalização em metodologia, no currículo dos cursos porque a gente tem disciplinas em inglês sendo incluídas e os cursos de extensão em outros idiomas [...]. (Entrevistados 3 e 4$)$

Isso também é identificado na Política de Internacionalização disponibilizada pela IES Federal, com ações que envolvem: (i) a ampliação da modalidade de internacionalização de disciplinas e dos conteúdos básicos e dos segmentos específicos; (ii) a atualização dos percursos e os meios de formação, quanto a conteúdo e estratégias pedagógicas, buscando uma sintonia com o que se faz de melhor em outros países; (iii) a estruturação de programas e cursos de modo que egressos sejam competitivos no mundo do trabalho globalizado; (iv) internacionalização dos currículos e programas visando à compatibilidade e à mobilidade de estudantes; (v) a discussão das mudanças curriculares e escopo de projetos de pesquisa para garantir compatibilização com parâmetros internacionais. Para o Assessor de Relações Internacionais desta IES: (9) "a reforma curricular que está sendo feita, visa a melhoria das metodologias e necessariamente a internacionalização dos currículos”. (Entrevistado 1).

Conforme demonstra a Figura 9 é possível perceber diversas citações e diversas relações entre as citações e os códigos. 
Figura 9 Ensino, pesquisa e extensão

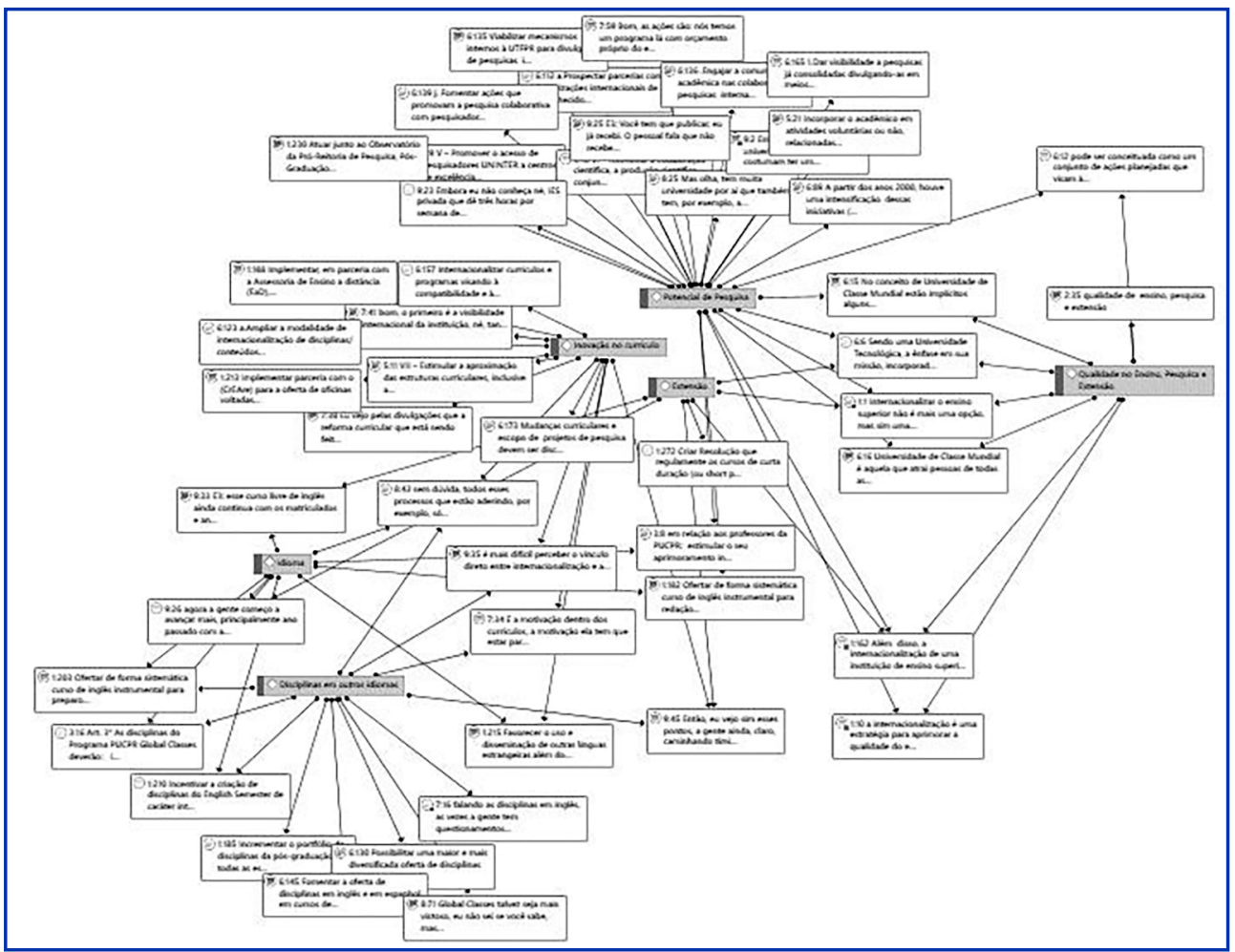

Fonte: Dados de pesquisa obtidos com o apoio do software Atlas.ti

Da mesma forma, são identificadas ações relativas à inovação curricular influenciadas pela internacionalização na IES Filantrópica, como: o favorecimento do uso e disseminação de outras línguas estrangeiras além do inglês nos currículos, e a implementação de parceria com áreas internas para a oferta de oficinas voltadas para a divulgação e aplicação dos conceitos de internacionalização do currículo.

\section{RESISTÊNCIA, DIFICULDADES, RISCOS E BENEFÍCIOS}

Nesta seção serão apresentados os principais resultados e discussões acerca dos códigos: resistências e dificuldades, riscos e benefícios.

Lustrea, Sava e Borca (2017) realizaram uma pesquisa com objetivo de proporcionar um melhor entendimento sobre as necessidades de uma melhor inter- 
nacionalização do ensino e da pesquisa, e forneceram algumas explicações possíveis sobre as dificuldades e resistências quanto as atividades internacionais. As dificuldades no processo de internacionalização percebidas nas IESs investigadas resultaram em pontos heterogêneos. Embora a fluência em inglês tenha sido citada como fator pró-internacionalização, ela também está presente em muitas respostas como uma barreira na internacionalização. A questão da acessibilidade para alunos e funcionários internacionais também foi mencionado. Adicionalmente, foi percebida baixa competência em estabelecer e manter relações internacionais. As principais vantagens percebidas quanto a internacionalização são: (i) o aumento da visibilidade institucional, atraindo recursos, tanto humanos, materiais e informacionais, criando equipes de pesquisa internacionais que atraem recursos substanciais; e (ii) o fato de poder ser uma fonte de validação de competências individuais. Os dados da presente pesquisa corroboram com os resultados da pesquisa de Lustrea et al. (2017).

Na IES Federal, segundo o Assessor de Relações Internacionais houve resistência em relação a dupla diplomação e na abertura das convalidações, principalmente relacionada a mudança de conceito referente a carga horária e o conteúdo equivalente:

(10) [...] nós começamos a perceber que precisava fazer uma mudança de conceito das convalidações, do que era carga horária equivalente, do que era conteúdo equivalente. Até então os nossos professores ou coordenadores só convalidavam a carga horária, o que o aluno fez lá fora fosse igual ou maior que $75 \%$ e o conteúdo tinha que ser praticamente igual. Mas se for pra fazer lá fora o que faz aqui não tem vantagem nenhuma. Então nós passamos alguns anos adaptando pra poder ter esse volume grande de alunos fazendo duplo diploma [...]. Antes com a visão e os regulamentos que nós tínhamos existia resistência das pessoas. Antes não era permitido fazer o acordo com reciprocidade porque depois quando você tem que convalidar tanto para aluno estrangeiro que estuda aqui como para o nosso que volta e convalidar as disciplinas em blocos, não item por item do ementário como eles pensavam. (Entrevistado 1)

Ainda de acordo com este Assessor existe também uma inércia. Logo, não há uma percepção da comunidade ser contra a internacionalização, porém há pessoas que pouco se importam e pouco se preocupam em pesquisar no exterior ou com interações com pessoas de fora. A dificuldade da língua também é apresentada, principalmente aos servidores e aos estudantes. Dificuldades financeiras também 
são percebidas quanto a internacionalização, pois muitos deixam remota a possiblidade de um intercâmbio internacional por questões financeiras. Segundo o Assessor, a internacionalização passa por mudança de mindset e mudança para maior flexibilização da forma de pensar.

Para o Diretor de Internacionalização da IES Filantrópica, a resistência já existiu na IES, porém, atualmente o cenário é favorável:

(11) Eu acho que já foi pior. Hoje o cenário é muito favorável, é muito positivo. É muito positivo porque eu acho que a gente conseguiu reverter. Na verdade, não é reverter. A gente conseguiu implementar essa cultura da internacionalização na universidade. Quando você fala em resistência, para mim ela tem dois aspectos: ou é uma resistência tipo uma mudança cultural, e as pessoas naturalmente são resistentes a mudanças de cultura, por razões óbvias. Elas estão acostumadas com a sua cultura, elas nasceram e foram criadas em uma determinada cultura. Quando você impõe uma mudança cultural ou pretende fazer uma mudança cultural, é natural que haja resistência. Medo do desconhecido. A gente afinal está confortável com o que conhecemos super bem. Então isso é uma coisa. A outra é que eu, como gestor, acredito que as pessoas têm que ser protagonistas das mudanças. Elas não podem ser reativas as mudanças. Então, desde que eu assumi a diretoria eu venho fazendo um trabalho de convencer as pessoas a pular no banco junto comigo. Então, ao invés de impor as ações, impor os processos, e depois impor metas e métricas para acompanhar esses processos, a gente gastou muito tempo, anos mesmo, muitos anos, tentando convencer a nossa comunidade de que internacionalização é uma coisa legal para todos eles. É legal para o estudante, para o professor, para o gestor. Portanto é legal para a universidade como um todo. Vai aumentar a qualidade no nosso ensino, vai aumentar a qualidade da nossa pesquisa. Vai trazer recursos para universidade. Vai ajudar a reter aluno, a atrair aluno. Portanto a universidade vai se tornar mais sustentável, mais rentável. Enfim, é bom para todo mundo quando ela [internacionalização] é bem-feita. É claro que no começo houve resistência, mas eu também fico feliz em te dizer que hoje eu percebo o contrário [...]. Hoje a demanda está vindo da comunidade e não o contrário. (Entrevistado 2)

Para as Coordenadoras da Diretoria Estratégica de Relações Internacionais na IES Privada, talvez o termo não seja resistência, mas uma expectativa da comunidade acadêmica que associa a internacionalização apenas como mobilidade. Para estas entrevistadas, esta comunidade trata a internacionalização como um conceito errôneo, pois a mobilidade faz parte da internacionalização, mas não é apenas isso. Outro ponto percebido envolve aspectos financeiros que representa uma limitação: 
(12) [...] eu vejo que existe um pouco de limitação da atuação do setor por conta de ser uma IES privada com fins lucrativos. Porque a internacionalização vai ter um lucro que é subjetivo. É um ganho na ampliação da pesquisa, um ganho na formação dos estudantes, na formação dos professores, ganho quanto ampliação da formação dos professores. Mas não tem um retorno, um lucro. Eu não tenho uma cifra. Eu tenho que colocar dinheiro para que isso funcione. Eu vejo uma certa resistência nesse aspecto da corporação mantenedora. (Entrevistados 3 e 4)

É possível verificar uma contradição entre a percepção da IES Filantrópica e a percepção da IES Privada quanto aos aspectos financeiros. Na IES Privada, o lucro é subjetivo e na IES Filantrópica a internacionalização trará recursos tangíveis para a universidade e a tornará mais sustentável e mais rentável.

Os entrevistados foram questionados também sobre os riscos e benefícios da internacionalização para as IES de maneira geral. Os resultados apresentados para esses códigos - Riscos e Benefícios - estão apresentados no Quadro 1, no qual é possível verificar um comparativo entre as três IES estudadas.

\section{Quadro 1 Riscos e Benefícios}

\begin{tabular}{|c|c|c|}
\hline Instituições & Riscos & Benefícios \\
\hline IES Federal & Não há riscos identificados & $\begin{array}{l}\text { Visibilidade Internacional } \\
\text { Balizamento } \\
\text { Dupla Diplomação }\end{array}$ \\
\hline $\begin{array}{c}\text { IES } \\
\text { Filantrópica }\end{array}$ & $\begin{array}{l}\text { Branding } \\
\text { Fuga de talentos } \\
\text { Indústria das acreditações e dos } \\
\text { rankings } \\
\text { Desconsiderar o contexto local }\end{array}$ & $\begin{array}{l}\text { Formação de profissionais e } \\
\text { líderes globais } \\
\text { Ferramenta de qualidade } \\
\text { Processo de inclusão }\end{array}$ \\
\hline IES Privada & Não há riscos identificados & $\begin{array}{l}\text { Potencial de pesquisa } \\
\text { Experiência global } \\
\text { Idiomas } \\
\text { Ciência }\end{array}$ \\
\hline
\end{tabular}

Fonte: dados de pesquisa (2020). 
São percebidos pelos entrevistados mais benefícios do que riscos quanto a internacionalização das IES, o que a torna um processo vantajoso para estas. No entanto, os riscos apresentados são consideráveis e as instituições precisam estar atentas para não fazer com que a internacionalização tenha apenas a função de: (i) compartilhar marcas; (ii) subir nos rankings; (iii) alterar os planos e políticas, negligenciando a missão, a visão e os valores, desconsiderando o contexto local, perdendo contato com a comunidade, o bairro e o estado que está inserida. As IES precisam estar atentas também quanto a possível fuga de talentos, pois na medida em que as IES se internacionalizam, o mundo passa a ser o limite para a comunidade de professores, alunos e colaboradores.

\section{Conclusão}

Por meio de um estudo qualitativo, utilizando dados primários e secundários e técnicas de análise de conteúdo e documental, o estudo teve como objetivo realizar um diagnóstico da internacionalização no ensino superior tendo o Brasil como case study.

Verificam-se convergências entre as percepções dos entrevistados sobre a internacionalização das IES brasileiras. Pela percepção do Assessor de Relações Internacionais da IES Federal, o setor público apresenta dificuldades e graus de importância diferentes quanto aos dados e as políticas internas. No entanto, de alguma forma tem se nivelado, não só por uma consciência internacional sobre necessidade da internacionalização, mas por influência das avaliações internas e externas. Ou seja, há uma cobrança de estar bem avaliado nos rankings. Porém, a internacionalização traz mais benefícios do que riscos. A consciência de quem tem a mente flexível e aberta para explorar novos conhecimentos e pessoas fora do país de origem e a consciência de observar o que e como se faz em outros lugares, ajuda demasiadamente no processo de desenvolvimento de instituições em crescimento para atingirem melhores patamares. É possível concluir que existe um maior foco na IES Federal em atividades de internacionalização que envolvem a dupla diplomação, bem como a pesquisa e a internacionalização em casa.

O nível de internacionalização das IES é percebido como muito heterogêneo pelo Diretor de Internacionalização da IES Filantrópica, pois atualmente no Brasil, 
existem universidades razoavelmente internacionalizadas e que possuem estratégias de internacionalização diferentes umas das outras. Por outro lado, há universidades que não ou pouco entendem o conceito de internacionalização, como ela se caracteriza e quais são seus impactos. Para este Diretor, a internacionalização no Brasil está em um estágio inicial, tendo muito a caminhar, principalmente quanto a gerar maior disseminação e quanto ao empenho das universidades em trabalhar na direção do real significado da internacionalização. Infere-se pelas percepções do entrevistado que esta IES está estruturada em dois eixos: a internacionalização dos 'portões para dentro', seguindo a premissa de que a verdadeira transformação acontece de dentro para fora, e a internacionalização dos 'portões para fora', seguindo a premissa de que o ponto de vista do outro é também fonte de enriquecimento.

A percepção das Coordenadoras da Diretoria Estratégica de Relações Internacionais da IES Privada é de que nas instituições com fins lucrativos, a internacionalização caminha em passos lentos, está vinculada e restrita ao entendimento de mobilidade acadêmica. Para estas entrevistadas, a pesquisa ainda não tem o escopo tão ampliado para que a internacionalização aconteça por meio dela. Nesta IES infere-se que a internacionalização está sendo realizada de duas formas claramente categorizadas e definidas, com propósitos e objetivos distintos: a internacionalização comercial e a internacionalização acadêmica. Existe maior foco para atividades internacionais que envolvem a mobilidade acadêmica.

A contribuição desta pesquisa repousa na comparação da internacionalização das instituições de ensino superior de três tipos de Universidades Brasileiras, ampliando o entendimento sobre o tema de pesquisa, relacionando a análise dos documentos institucionais com a percepção dos especialistas destas IES. Uma limitação desta pesquisa se refere a amostra, que não envolveu todos os tipos de IES de acordo com a classificação do MEC, como as: instituições não universitárias, instituições públicas estaduais e municipais e instituições privadas sem fins lucrativos comunitárias. Outra limitação repousa na comparação entre IES do mesmo estado brasileiro.

Quanto a originalidade do estudo, notam-se pesquisas focadas em analisar como vem acontecendo o processo de internacionalização nas IES, bem como seus riscos, benefícios e ações. Porém, estas pesquisas anteriores avaliam as IES 
de forma individualizada, sem compreender comparativamente a internacionalização nos diversos tipos de instituições brasileiras e sem fazer uma comparação nacional e internacional, tendo em visto que essa comparação pode apresentar novas possibilidades de internacionalizar as IES. Em tempos de pandemia, surgida em 2020 pelo vírus COVID-19, a vacina pode ser mencionada como um grande resultado da cooperação internacional entre instituições de ensino de pesquisa e iniciativas privadas.

\section{Agenda de Pesquisas Futuras}

Para trabalhos futuros é sugerido estudos com dados quantitativos utilizando métodos de apoio à tomada de decisão a fim de compreender a influência da internacionalização para a realização da missão e da visão de futuro das Universidades Brasileiras. Também é sugerido pesquisas que sejam realizadas considerando todos os tipos de IES de acordo com a classificação do MEC. Sugere-se também pesquisas comparativas entre IES de diferentes estados brasileiros, e comparações entre IES do Brasil e IES de diferentes países.

\section{Referências}

ALSHARARI, N. M. Internationalization of the higher education system: an interpretive analysis. International Journal of Educational Management. v. 32, n. 3, p. 359 381, abr. 2018. DOI: 10.1108/IJEM-042017-0082.

ALSHARARI, N. M. Internationalization market and higher education field: institutional perspectives. International Journal of Educational Management, v. 34, n. 2, p. 315-334, ago. 2019. DOI: 10.1108/IJEM12-2018-0402.

ALTBACH, P. G.; KNIGHT, J. The Internationalization of higher education: motivations and realities. Journal of Studies in International Education, v. 11, n. 3/4, p. 290-305, set. 2007. DOI: 10.1177/1028315307303542. AYOUBI, R. M.; MASSOUD, H. K. The strategy of internationalization in universities: A quantitative evaluation of the intent and implementation in UK universities. International Journal of Educational Management, vol. 21, n. 4, p. 329-349, maio. 2007. DOI: 10.1108/09513540710749546.

BARDIN, L. Análise de conteúdo. São Paulo: Edições 70, 2011.

BAS, D. C. M.; BOQUERA, M.; CAROT, J. M. Measuring internationalization performance of higher Education institutions through composite indicators. In: INTERNATIONAL TECHNOLOGY, EDUCATION AND 
DEVELOPMENT CONFERENCE, 2017, Valencia. Anais...Valencia: Conference Paper, mar. 2017, p. 31493156. DOI: 10.21125/inted.2017.0815.

BEDENLIER, S.; KONDAKCI, Y.; ZAWACKI-RICHTER, O. Two decades of research into the internationalization of higher education: Major themes in the Journal of Studies in International Education (1997-2016). Journal of Studies in International Education, v. 22, n. 2, p. 108-135, 2018. DOI: 10.1177/1028315317710093.

GUO, Y.; GUO, S. Internationalization of Canadian higher education: Discrepancies between policies and international student experiences. Studies in Higher Education, v. 42, n. 5, p. 851-868, mar. 2017. DOI: 10.1080/03075079.2017.1293874.

HUANG, L. Co-curricular activity-based intercultural competence development: students' outcome of internationalisation at universities. Innovations in Education and Teaching International, v. 54, n. 3, p. 184-193. 2017. DOI: 10.1080/14703297.2016.1184098.

JUNIOR, H. A. A contribuição da estratégia como prática para o estudo da formação de estratégias em universidades. RPGE-Revista on line de Política e Gestão Educacional, v. 20, n. 2, p. 337-358, dez. 2016. DOI: 10.22633/rpge.v20.n2.9464.

Lei 9394/1996. Lei de Diretrizes e Bases da Educação Nacional, LDB. São Paulo: Saraiva, 1996.

LUSTREA, A.; SAVA, S.; BORCA, C. Internationalization of Higher Education from Teachers' Point of View. In: EDU WORLD 2016 7TH INTERNATIONAL CONFERENCE. 2017. Romênia. Anais... Romênia: EpSBS, 2017. DOI: 10.15405/epsbs.2017.05.02.50.

KAHN, H. E.; AGNEW, M. Global learning through difference: Considerations for teaching, learning, and the internationalization of higher education. Journal of Studies in International Education, v. 21, n. 1, p. 52-64. 2017. DOI: 10.1177/1028315315622022.

KNIGHT, J. Checkpoints for an internationalization strategy. Canadian Bureau for International Education, n. 7. p. 1-15. 1994.

KNIGHT, J. Concepts, Rationales, and Interpretive Frameworks in the Internationalization of Higher Education. SAGE Publications. p. 27-42, jan. 2012. DOI: 10.4135/9781452218397.n2.

KNIGHT, J. Is Internationalisation of Higher Education Having an Identity Crisis?. In: Maldonado-Maldonado A., Bassett R. (eds) The Forefront of International Higher Education. Higher Education Dynamics, v. 42. Springer: Dordrecht, 2014, p. 75-87. DOI: 10.1007/978-94-007-7085-0_5.

KNIGHT, J. Updated definition of internationalization. International Higher Education, n. 33, mar. 2015. DOI: 10.6017/ihe.2003.33.7391.

MARANHÃO, C. M. S. DE A.; DUTRA, I. I. C.; MARANHÃO, R. K. DE A. Internacionalização do ensino superior: um estudo sobre barreiras e possibilidades. Administração: Ensino e Pesquisa, v. 18, n. 1, p. 9-38, jan. 2017. DOI: 10.13058/raep.2017.v18n1.458.

MARGON, J.; POUBEL, L. Tomada de decisão estratégica em organizações complexas: a dinâmica de processos decisórios colegiados em uma universidade pública. Pensamento \& Realidade, v. 31, n. 3, p. 88-106, 2016.

MENG, Q.; ZHU, C.; CAO, C. An Exploratory Study of Chinese University Undergraduates Global Competence: Effects of Internationalisation at Home and Motivation. Higher Education Quarterly. v. 71, n. 2, p. 159-181, mar. 2017. DOI: 10.1111/hequ.12119. 
MEYER JR, V.; PASCUCCI, L.; MANGOLIN, L. Gestão estratégica: um exame de práticas em universidades privadas. Revista de Administração Pública, v. 46, n. 1, p. 49-70, jan./fev. 2012. DOI: 10.1590/ S0034-76122012000100004.

MOK, K. H. Does internationalisation of Higher Education still matter? Critical reflections on student learning, graduate employment and faculty development in Asia. Higher Education Quarterly, v. 72, n. 3, p. 183-193. jul. 2018. DOI: 10.1111/hequ.12170.

MORITZ, M. O. et al. A implantação do planejamento estratégico em organizações complexas: o caso da Universidade do Estado de Santa Catarina. Revista Gestão Universitária na América Latina-GUAL, v. 5, n. 1, p. 228-249, jan./fev./mar./abr. 2012.

MOROSINI, M. C.; DALLA CORTE, M. G. Teses e realidades no contexto da internacionalização da educação superior no Brasil. Revista Educação em Questão, v. 56, n. 47, p. 97-120, jan./mar. 2018. DOI: 10.21680/1981-1802.2018v56n47ID14000.

PASCUCCI, L.; MEYER JR, V. Estratégia em contextos complexos e pluralísticos. Revista de administração contemporânea, v. 17, n. 5, p. 536-555, set./out. 2013. DOI: 10.1590/S1415-65552013000500003. PATEL, F. Deconstructing internationalization: Advocating glocalization in international higher education. Journal of International and Global Studies, v. 8, n. 2, p. 64-82, abr. 2017.

PROLO, I. et. al. Internacionalização das Universidades Brasileiras - Contribuições do Programa Ciência sem Fronteiras. Administração: Ensino e Pesquisa, v. 20, n. 2, p. 319-361, maio. 2019. DOI: 10.13058/ raep.2019.v20n2.1330.

ROMANI-DIAS, M.; CARNEIRO, J.; BARBOSA, A. S. Internationalization of higher education institutions: the underestimated role of faculty. International Journal of Educational Management, v. 33, n. 2, p. 300316, fev. 2019. DOI: 10.1108/IJEM-07-2017-0184.

RAMOS, M. Y. Internacionalização da pós-graduação no Brasil: lógica e mecanismos. Educação e Pesquisa, v. 44, p. e161579, 2018. DOI: 10.1590/s1517-9702201706161579.

SEEBER, M. Framework and operationalisation challenges for quantitative comparative research in higher education. Higher Education Quarterly. v. 74, n. 2, p. 162 175, dez. 2019. DOI: 10.1111/hequ.12245. SNODIN, N. Mobility experiences of international students in Thai higher education. International Journal of Educational Management, v. 33, n. 7, p. 1653-1669, nov. 2019. DOI: 10.1108/IJEM-07-2018-0206.

TRESHCHEVSKY, Y.; IGOLKIN, S. L.; SHATALOV, M. Internationalization of the educational services market through development of the system of remote education: Possibilities and barriers. International Journal of Educational Management, v. 33, n. 3, p. 478-485, abr. 2019. DOI: 10.1108/IJEM-08-20180266.

VALCKE, J.; MURPHY, A. C.; COSTA, F. l'analisi linguistica e letteraria. In: VALCKE, J.; MURPHY, A. C.; COSTA, F. EMI - A Tool for the Internationalisation of Higher Education. Itália: EDUCatt, 2017. p. 255-260. WIHLBORG, M.; ROBSON, S. Internationalisation of higher education: drivers, rationales, priorities, values and impacts. European Journal of Higher Education, v. 8, n. 1, p. 8-18, 2018. DOI: 10.1080/21568235.2017.1376696. 


\section{Apêndice - Roteiro de Entrevista Semiestruturada}

O presente roteiro de entrevista tem por finalidade: realizar um diagnóstico da internacionalização das instituições de ensino superior entre três tipos de Universidades Brasileiras. As informações serão mantidas sob sigilo e a identidade da IES não será divulgada.

\section{Consciência}

De maneira geral, como o Sr. (a) avalia a questão da internacionalização das instituições de ensino superior?

Há uma política formal de internacionalização na IES? Se sim, qual é essa política?

Quais os momentos marcantes da instituição relacionados à internacionalização e quais os principais envolvidos?

A internacionalização está declarada na Visão, Missão e Valores da IES?

\section{Compromisso}

Qual é o papel do seu departamento/Escola na formulação da política de internacionalização da IES?

Os órgãos governamentais, como o MEC, a CAPES e o CNPq, desempenham algum papel no processo de internacionalização da IES?

Há alguma resistência ao processo de internacionalização? Se sim, de onde vem essa resistência? (estudantes, professores, quadro administrativo...).

\section{Planejamento}

Quais as principais razões, motivações que têm levado a IES a se internacionalizar?

Quais são as prioridades em termos de internacionalização em seu departamento/Escola: ensino, pesquisa ou extensão?

Existe alguma área priorizada? Graduação ou Pós-Graduação?

Houve impacto financeiro em seu departamento/Escola, seja investimentos, despesas, lucro, em virtude da internacionalização? 


\section{Operacionalização}

Quais ações estão sendo tomadas para a internacionalizar o corpo docente e discente na IES?

Em seu departamento/Escola existem processos envolvidos com estes fatores?

Quais são as três principais ações de internacionalização promovidas pelo seu departamento/Escola na IES?

\section{Revisão}

O processo de internacionalização trouxe atualizações curriculares, novas metodologias de ensino, inclusão de conteúdos internacionais? Quais os três principais benefícios da internacionalização na IES? Quais os três principais riscos da internacionalização na IES?

\section{Reforço}

Existem iniciativas desenvolvidas ou em desenvolvimento referente a reconhecimento e recompensas para professores, funcionários e participação de estudantes em relação ao processo de internacionalização na IES?

Os indicadores de desempenho podem colaborar para o processo de internacionalização da IES?

Qual são os indicadores de internacionalização utilizados na IES? 